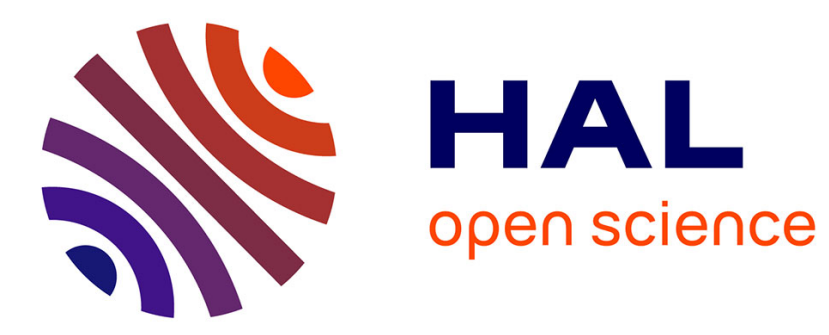

\title{
Molecular Tectonics: Design of Hybrid Networks and Crystals Based on Charge-Assisted Hydrogen Bonds
}

Sylvie Ferlay, Mir Wais Hosseini

\section{To cite this version:}

Sylvie Ferlay, Mir Wais Hosseini. Molecular Tectonics: Design of Hybrid Networks and Crystals Based on Charge-Assisted Hydrogen Bonds. Functional Supramolecular architectures for organic electronics and nanotechnology, 2011, 10.1002/9783527689897.ch07 . hal-02301261

\section{HAL Id: hal-02301261 \\ https://hal.science/hal-02301261}

Submitted on 27 Nov 2020

HAL is a multi-disciplinary open access archive for the deposit and dissemination of scientific research documents, whether they are published or not. The documents may come from teaching and research institutions in France or abroad, or from public or private research centers.
L'archive ouverte pluridisciplinaire HAL, est destinée au dépôt et à la diffusion de documents scientifiques de niveau recherche, publiés ou non, émanant des établissements d'enseignement et de recherche français ou étrangers, des laboratoires publics ou privés. 


\section{7 \\ Molecular Tectonics: Design of Hybrid Networks and Crystals Based on Charge-Assisted Hydrogen Bonds}

Sylvie Ferlay and Mir Wais Hosseini

\section{1 \\ Introduction}

Molecular crystals are periodic three-dimensional arrangement of molecules in the solid state. This category of materials is defined by the chemical nature of the molecular components constituting the crystal and interactions between them. The crystallization process leading to the organization of molecules in ordered periodic architectures in the solid state is a typical example of self-assembly [1]. The latter, governed by the rules of supramolecular chemistry [2], leads to spontaneous generation of complex molecular architectures from molecular units through reversible intermolecular interactions. By analogy, whereas molecular chemistry deals with the design and the synthesis of individual units constituting the crystal, their self-assembly [3], through diverse intermolecular interactions, results from concepts developed in supramolecular chemistry. The area of solid-state synthesis dealing specifically with the design and formation of molecular crystals is called crystal engineering [4]. Within the vast area of crystal engineering, the molecular tectonics [5] approach is based on the construction and analysis of molecular crystals, seen as periodic architectures called molecular networks [6], individual building blocks named tectons, and their mutual interactions through specific recognition patterns called supramolecular synthons [7]. Thus, for this approach, the main goal is the design and formation of molecular networks [8] and their packing in the crystalline phase using structurally defined and energetically programmed molecular tectons [9]. A tecton is defined as an active molecular construction unit or building block bearing recognition sites [10]. Thus, molecular networks may be seen as molecular assemblies formed between complementary molecular tectons capable of mutual interactions through one or several molecular recognition events, which define structural nodes of the architecture. The dimensionality of molecular network (1D, 2D, or 3D) depends on the number of translations operating at the level of the assembling nodes. Molecular networks may be formed in any type of condensed media such as solution, gel, or solid state. Within the last category, owing to the presence of short- and long-range order, the crystalline phase has been extensively 
used because of the possibility of accurate structural studies using X-ray diffraction methods.

Among many factors governing the formation of crystals, recognition patterns or supramolecular synthons, which appear during the crystallization process, are of prime importance allowing, to a certain extent, to predict the final crystal structure [11]. This aspect has been theoretically investigated using different approaches [12]. However, it is worth noting that owing to our limited knowledge of all subtle intermolecular interactions governing the formation of the crystalline phase, the complete understanding of the formation of molecular networks and their packing leading to the crystal remains so far unreachable [13]. Nonetheless, our current level of knowledge allows to control some of the intermolecular interactions with precision, that is, the appearance of recognition patterns with a good degree of reliability, by properly designing molecular tectons. Thus, one may predict the formation of molecular networks and in some cases their packing in the crystalline phase.

The three main features governing the design of molecular networks are (i) the design of recognition patterns linking a self-complementary or two or several complementary tectons, (ii) the geometrical aspects dealing with the localization of the interaction sites, and (iii) the nature of intermolecular forces allowing the interconnection of tectons. The latter, by principle, must be reversible in order to allow self-repairing processes to take place during the construction events. Different reversible intermolecular interactions such as H-bonding [14] and coordination bonding [15] have been widely explored over the last two decades. Other forces such as $\pi$-stacking interactions [16] or inclusion processes based on van der Waals interactions [17] have also been used for the construction of inclusion molecular networks in the solid state.

For the design of the structural nodes, a possible reason for the extensive use of $\mathrm{H}$ bond interaction is its rather directional nature [18]. In terms of strength, H-bond ranges from weak (about a fraction of $\mathrm{kcal} \mathrm{mol}^{-1}$ ) to moderate interactions (about $5-10 \mathrm{kcal} \mathrm{mol}^{-1}$ ) [19]. Consequently, in order to increase the robustness of the architecture, one needs to enhance the interaction energy between the tectons. This may be achieved by combining $\mathrm{H}$-bonding with less directional but more energetic electrostatic charge-charge interactions. This type of recognition pattern is called charge-assisted $\mathrm{H}$-bonds (CAHBs) [20]. It results from the interaction between charged hydrogen bond donors (D) and acceptors (A) leading to the $\left({ }^{+} \mathrm{D}-\mathrm{H} \cdots \mathrm{A}^{-}\right)$supramolecular synthon.

The majority of molecular networks reported to date are based on nonionic $\mathrm{H}$ bonds [14]. However, several cases of charge-assisted hydrogen bonding have been also described in the literature. Some of these cases will be presented in the following section.

Although at the initial steps of this approach, investigators were interested in the understanding and control of structural features governing the formation of molecular networks in the crystalline phase, that is, mainly the connectivity patterns, since a decade, considerable effort has been made in obtaining functional molecular materials with specific properties in the area of, for example, optics [21], magnetism [22], or porosity [23]. 

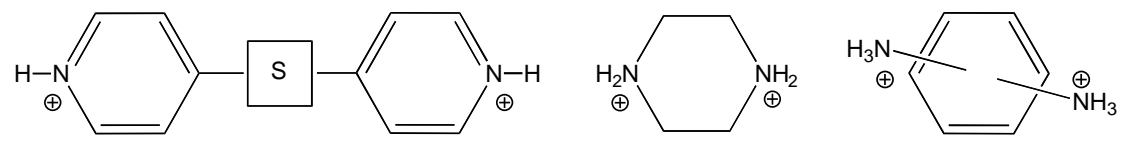

Figure 7.1 Selected organic dications usually used in the formation of CAHB networks.

\section{2}

\section{Examples of Robust Charge-Assisted H-Bonded (CAHB) Networks}

In recent years, only few examples of CAHB networks have been reported in the literature. We will give here a short (nonexhaustive) overview of described cases. It is interesting to note that most of the networks are based on ${ }^{+} \mathrm{N}-\mathrm{H} \cdots \mathrm{O}^{-}$, ${ }^{+} \mathrm{N}-\mathrm{H} \cdots \mathrm{N}^{-}$, or ${ }^{+} \mathrm{N}-\mathrm{H} \cdots \mathrm{X}^{-}$type of recognition patterns. Pyridinium, ammonium, amidinium, and guanidinium derivatives, all bearing a protonated $\mathrm{N}$-atom, are among the most used hydrogen bond donors. Some of the used dicationic pyridinium and ammonium units are depicted in Figure 7.1.

\subsection{1}

\section{Organic Networks}

A new type of charge-assisted purely organic network was proposed by Ward using a combination of the guanidinium group as the cationic tecton and monosulfonate and disulfonate derivatives as anionic partners. This combination usually forms a $(6,3)$ bidimensional network (a sheet) in which each ion participates in six ${ }^{+} \mathrm{N}-\mathrm{H} \cdots \mathrm{O}^{-}$ hydrogen bonds. The organic substituent (R group) of the sulfonate moiety acts as a pillar supporting the inclusion cavities between the sheets. By changing the nature of the $\mathrm{R}$ group, a rich family of architectures has been obtained (Figure 7.2) [24]. Furthermore, the same group has elegantly demonstrated the possibility of modulating the pore size through the nature and length of the pillar and thus creating porous materials able of including specific guest molecules [25].

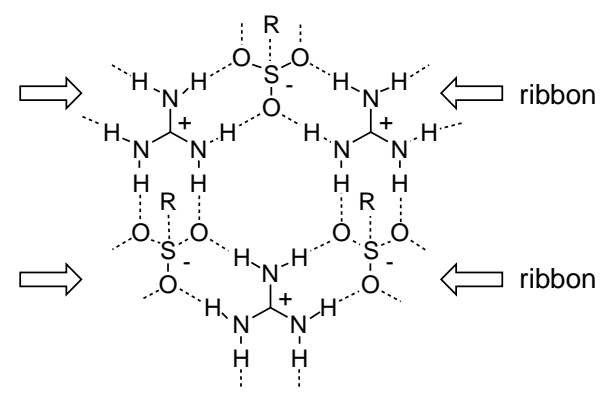

Figure 7.2 Quasi-hexagonal (6,3) 2D network formed upon combining the guanidinium cation with sulfonate anions. Reproduced with permission from Ref. [24a]. Copyright 2009 American Chemical Society. 

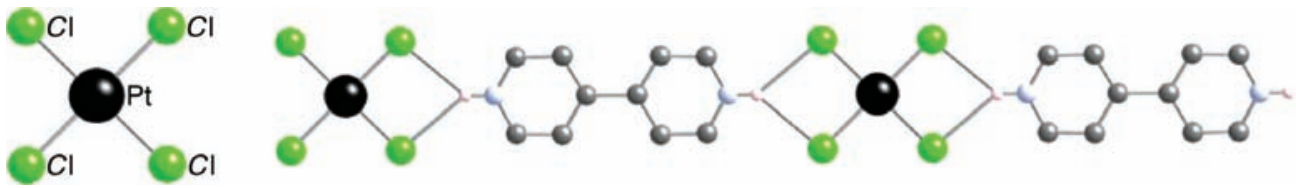

Figure 7.3 Tetrachloroplatinate (left) and a ID CAHB network (right) formed in the presence of 4,4'-bipyridine.

\subsection{2}

\section{Inorganic Networks}

A new class of ionic metalloorganic architectures have been developed recently by G. Orpen and coworkers using perhalogenometallate complexes such as (i) square planar or tetrahedral $\left[\mathrm{M}^{\mathrm{II}} \mathrm{X}_{4}\right]^{2-}(\mathrm{X}=\mathrm{Cl}, \mathrm{M}=\mathrm{Pd}, \mathrm{Pt}, \mathrm{Co}, \mathrm{Zn}, \mathrm{Hg}, \mathrm{Mn}, \mathrm{Cd}$, and $\mathrm{Pb} ; \mathrm{X}=\mathrm{Br}$, $\mathrm{M}=\mathrm{Pd}$, Co, $\mathrm{Zn}$, and $\mathrm{Mn}$ ); (ii) octahedral $\left[\mathrm{M}^{\mathrm{IV}} \mathrm{Cl}_{6}\right]^{2-}(\mathrm{M}=\mathrm{Os}$ and $\mathrm{Pt})$; (iii) trigonal bipyramidal $\left[\mathrm{Fe}^{\mathrm{III}} \mathrm{Cl}_{5}\right]^{2-}$; (iv) planar $\left[\mathrm{Cu}_{2}{ }_{2} \mathrm{Cl}_{6}\right]^{2-}$, and (v) square pyramidal $\left[\mathrm{Sb}^{\mathrm{III}} \mathrm{Cl}_{5}\right]^{2-}$ anionic complexes. The combination of these anions with pyridinium or bipyridine cations leads to a variety of architectures [26]. The ${ }^{+} \mathrm{N}-\mathrm{H} \cdots \mathrm{X}^{-}$recognition pattern is responsible for the formation of networks. The connectivity of the network is governed by the shape and orientation of the H-bonds taking place between anions and cations. An example of 1D H-bonded network is shown in Figure 7.3.

In order to extend the variety of networks, the nature of the pyridinium derivative was varied [27]. A similar approach has also been followed by Brammer and coworkers [28].

The strategy was further extended to other hydrogen bond acceptors such as metaldithiolate, metal 1,2-dithiomaleonitrile, tetracyanometallate, and thiocyanatometallate complexes [29].

Other examples involving hybrid organic/inorganic CAHB networks (with both organic and metallic tectons) were recently reported by Sutter and coworkers [30]. For example, using the ${ }^{+} \mathrm{N}-\mathrm{H} \cdots \mathrm{O}^{-}$-type recognition pattern, combinations of zirconiumtetraoxalate $\left[\mathrm{Zr}^{\mathrm{IV}}\left(\mathrm{C}_{2} \mathrm{O}_{4}\right)_{4}\right]^{4-}$ with different dicationic units afford different extended networks. The same type of approach was also reported by Sevov and coworkers [31]. They used metal complexes bearing a diamino and oxalate chelates (Figure 7.4) as H-bond donors and sulfonate derivatives as H-bond acceptors.

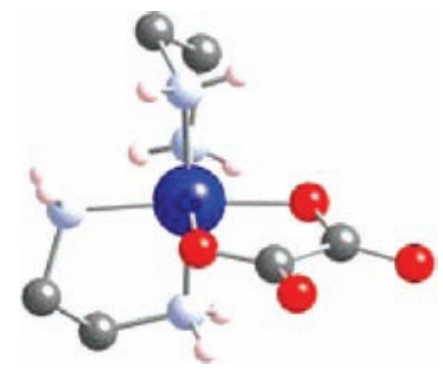

Figure 7.4 Building block [Co(en $\left.)_{2} \mathrm{Ox}\right]$ used for the formation of CAHB networks. 


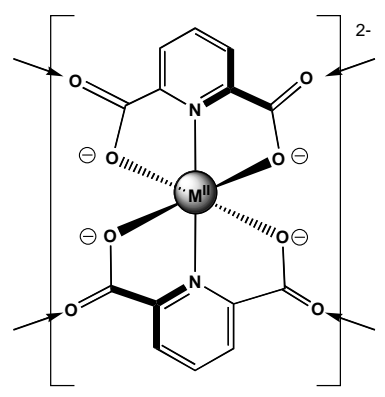

(a)

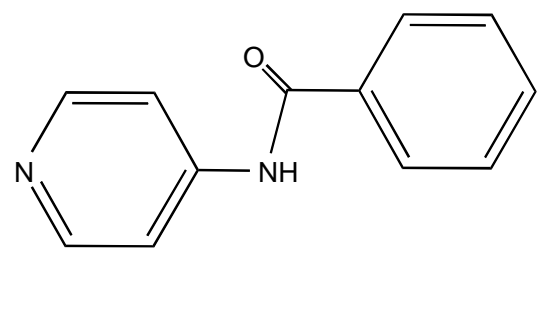

(b)

Figure 7.5 Metallatecton $\left[\mathrm{M}^{\prime \prime}(2,6 \mathrm{pdca})_{2}\right]^{2-}$ (a) and pyridyl benzamide-based ligand (b) used for the construction of hybrid organic/inorganic $\mathrm{H}$-bonded networks.

Hybrid networks, based on organic tectons offering structural flexibility and inorganic tectons imposing rigidity and bringing physical properties, may lead to functional crystals. This transition from structural to functional aspects remains so far almost unachieved and only very few examples have been reported till now. These cases will be presented hereafter and in the section dealing with our own investigations using bisamidinium-type tectons.

The first examples were given by Palmore and coworkers, as well as by McDonald et al.. They combined the imidazolium cation with metallopyridinecarboxylate complexes (Figure 7.5a) [32]. Stang and coworkers used pyridyl benzamide (Figure 7.5b) as a self-complementary unit acting as a ligand toward metal cations and as both $\mathrm{H}$-bond donor and acceptor [33]. In both cases, magnetic networks as well as layered crystalline materials with possible applications in optics have been obtained.

Finally, the last example by Dalrymple and Shimizu [34] describes the formation of highly porous materials. This group used the formation of ${ }^{+} \mathrm{N}-\mathrm{H} \cdots \mathrm{O}^{-}$-type recognition pattern generated upon combining organosulfonates and metalloamino-based tectons.

We have described here several examples reported in the literature dealing with combinations of $\mathrm{H}$-bond donors and acceptors leading to the formation of a variety of architectures based on charge-assisted H-bonded networks. In the following section, we shall report on our own extensive studies dealing with amidinium-based tectons.

\section{3}

\section{Charge-Assisted H-Bonded Networks Based on Amidinium Tectons}

\subsection{1}

\section{Amidinium-Based Tectons}

Bisamidinium dications (Figure 7.6) are interesting candidates as symmetric building blocks for the design of CAHB molecular networks. Indeed, due to the presence 

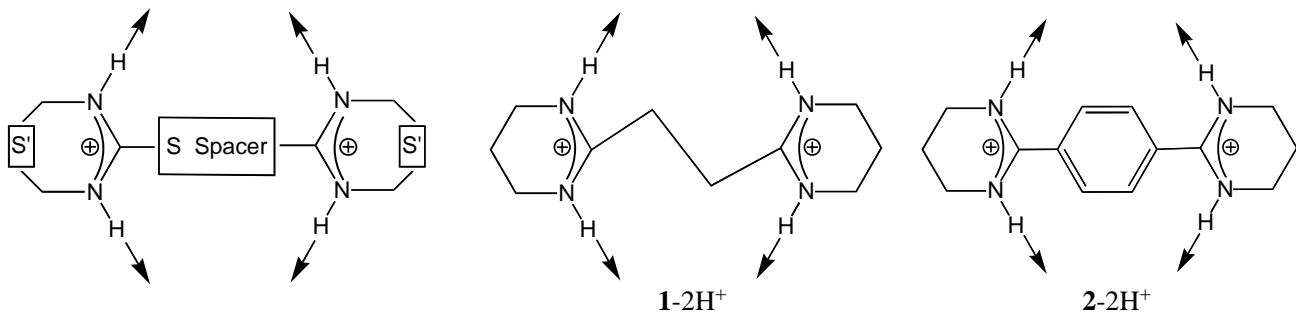

Figure 7.6 Schematic representation of the bisamidinium cation used for the formation of CAHB networks.

of four acidic $\mathrm{N}-\mathrm{H}$ protons, oriented in a divergent fashion, this type of cationic unit may act as a tetra-H-bond donor. The distance between two nitrogen atoms on the same face of the building block can be adjusted by the nature of the spacer S. For example, although for the short ethyl spacer $\left(1-2 \mathrm{H}^{+}\right)$, a distance of about $5.2 \AA$ between the two $\mathrm{N}$-atoms located on the same face may be imposed [35], this distance may be increased to $7.0 \AA$ by using the phenyl spacer $\left(2-2 \mathrm{H}^{+}\right)[36]$. Furthermore, distance between the two $\mathrm{N}$-atoms of the two amidinium groups may be finely tuned by varying the size of the cyclic amidinium moieties through the nature and length of the spacer $\mathrm{S}^{\prime}$ (5-, 6-, and 7-member rings). By imposing all these metrics, one may control the mode of recognition of different anions by the dicationic building block. For example, one may impose a bisdihapto mode (two dihapto modes of $\mathrm{H}$-bonding, one on each side) or a dihapto and bismonohapto or even a tetra-monohapto mode of H-bonding.

\section{3 .2}

\section{Organic Networks Based on Amidinium Tectons}

It has been shown that symmetric bisamidinium cations lead to the formation of purely organic CAHB networks with various and controlled dimensionality when combined with carboxylates as well as sulfonate and phosphonate derivatives [37].

Indeed, tecton $1-2 \mathrm{H}^{+}$(Figure 7.6) for which the spacer $\mathrm{S}$ is an ethyl group, owing to the distance separating the two amidinium moieties, is particularly well suited for the recognition of carboxylate anion through a dihapto mode of $\mathrm{H}$-bond of the ${ }^{+} \mathrm{N}-\mathrm{H} \cdots \mathrm{O}^{-}$type. Using this type of recognition pattern, a series of molecular networks with tunable dimensionality have been generated [36, 38]. Two examples, describing the formation of a 1D network with benzene 1,4-dicarboxylate and of a 2D network with fumarate, are given in Figure 7.7a and b, respectively.

Other examples of nonmetallic networks generated upon combining bisamidinium cations with phosphate derivatives have been also reported [39].

Another example of purely organic networks containing bisamidinium-type tectons is based on ${ }^{+} \mathrm{N}-\mathrm{H} \cdots \mathrm{N}^{-}$recognition pattern. This was achieved with an organic tectons offering terminal cyano groups $\left(2,2^{\prime}-\left(1,4-\right.\right.$ phenylene)pyrimidine $\left.{ }^{2+}\right)$ such as polycyano anions (Figure 7.8) [40]. The anion, possessing a $C_{3}$ symmetry, due to metric constraints, acts as a tetra-H-bond acceptor and the 1D network is formed 


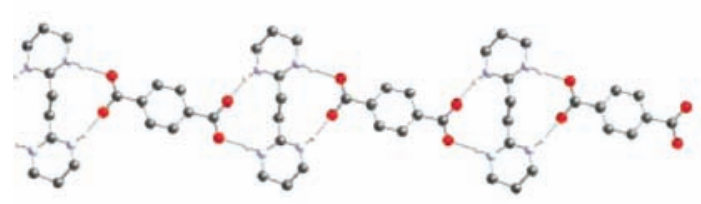

(a)

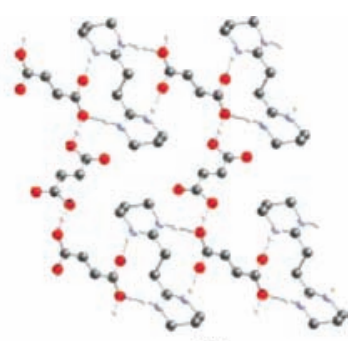

(b)

Figure 7.7 ID and 2D H-bonded networks formed with benzene 1,4-dicarboxylate (a) and fumarate (b) anions.

through only four H-bonds per hexacyano unit. In other words, of the six cyano groups, two are not involved in the formation of the 1D network.

An additional example of purely organic functional 1D network based on a bisamidinium cation combined with a benzenecarboxylate derivative bearing the nitronyl nitroxide spin careers was reported [41]. The 1D network obtained displays weak ferromagnetic interaction. Finally, by combining bisamidinium cations with benzene carboxylate derivatives bearing mesogenic groups, liquid crystalline-type materials have been obtained [42].

\subsection{3}

\section{Inorganic Networks Based on Amidinium Tectons}

Few examples of hybrid networks generated upon combining bisamidinium-based tectons with organometallic anionic tectons, also called metallatectons, are given in the following section.

\subsubsection{Metallatectons Bearing a Carboxylate at Their Periphery}

Exploiting the propensity of bisamidinium-based tecton $1-2 \mathrm{H}^{+}$to recognize carboxylate anions through a dihapto mode of $\mathrm{H}$-bonding of the ${ }^{+} \mathrm{N}-\mathrm{H} \cdots \mathrm{O}^{-}$type, a series of 1D networks based on ferrocenyl derivatives bearing two carboxylate moieties at their periphery were obtained (Figure 7.9) [43].

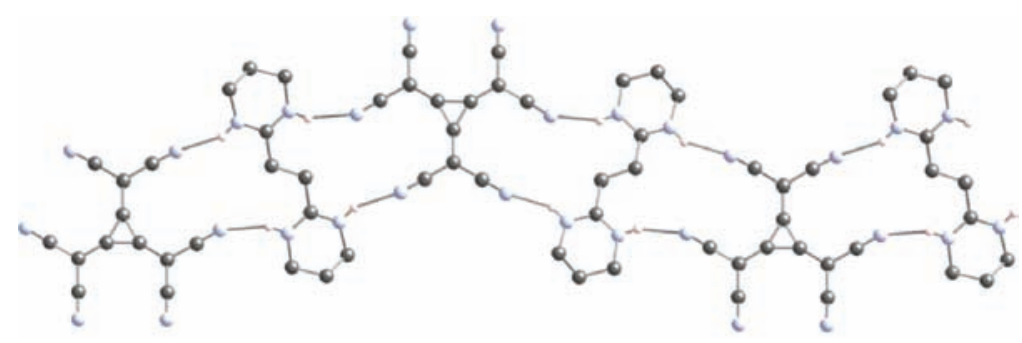

Figure 7.8 ID CAHB network formed between $1-2 \mathrm{H}^{+}$and hexacyanocyclopropanediide ${ }^{2-}$. 

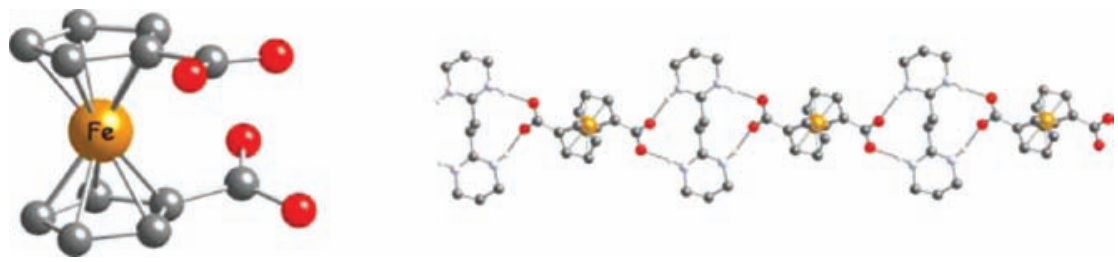

Figure 7.9 Ferrocenedicarboxylate anion (left) and 1D CAHB network (right) formed using the tecton $1-2 \mathrm{H}^{+}$.

A further extension consisting in combining charge-assisted hydrogen bonding with coordination bond formation was also achieved. Thus, 2,2'-bipyridine or phenanthroline derivatives bearing two carboxylate groups have been used as both coordinating ligand toward transition metal cations and as $\mathrm{H}$-bond acceptor units. In the presence of silver cation, these ligands form 2/1 (L/M) complexes bearing four carboxylate moieties oriented in a divergent fashion. These species behave as metallatectons and in the presence of dicationic organic tectons such as $1-2 \mathrm{H}^{+}$, they lead to the formation of cationic 2D networks. The formation of the latter results from the recognition of the dicarboxylate moieties by the bisamidinium tecton through a dihapto mode of H-bonding. This is an elegant example of a threecomponent system (Ag, L, and bisamidinium) combining two different types of recognition events and thus two different connectivities (Figure 7.10) [44].

\subsubsection{Oxalatometallate as H-Bond Acceptor}

As already demonstrated [30], oxalatometallate complexes may be used as hydrogen bond acceptors. The combination of octahedral bisoxalatometallate $[\mathrm{Cr}$ $(\text { ox })_{2}$ bipy $]^{2-}$ [45] with 2-2 $\mathrm{H}^{+}$(Figure 7.6) [46] leads to a 1D network (Figure 7.11). The formation of the network results from the recognition of the terminal oxygen
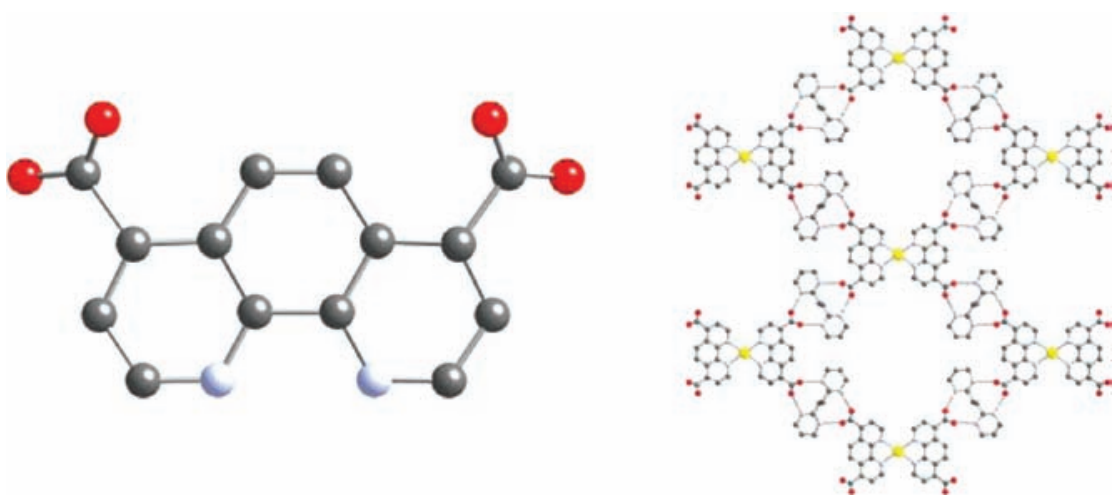

Figure 7.10 4,9 phenanthrolinedicarboxylate L (left) and 2D CAHB network (right) formed between $1-2 \mathrm{H}^{+}, \mathrm{L}$, and silver cation. 

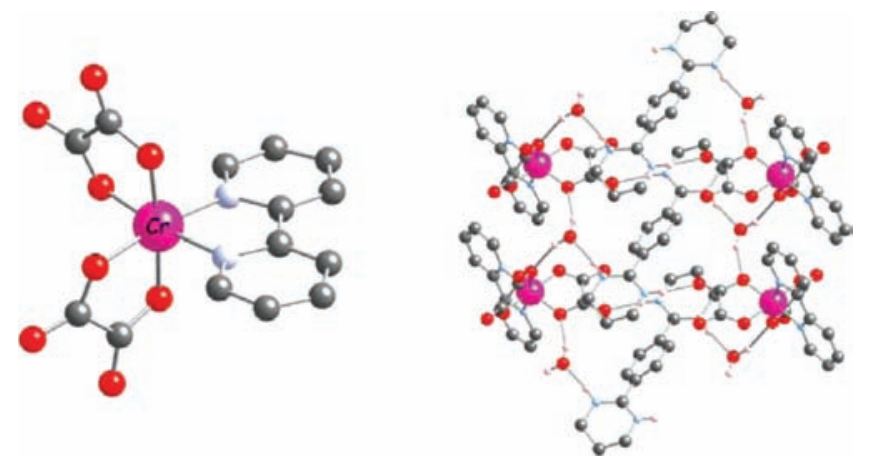

Figure 7.11 $\left[\mathrm{Cr}(\mathrm{ox})_{2} \text { bipy }\right]^{-}$complex (left) and 1D CAHB network (right) formed in the presence of $1-2 \mathrm{H}^{+}$.

atoms of the metal complex by the amidinium moiety through ${ }^{+} \mathrm{N}-\mathrm{H} \cdots \mathrm{O}^{-}$-type interactions.

\subsubsection{Thiocyanatometallate as H-Bond Acceptor}

For the formation of $\mathrm{H}$-bonded networks, combinations of cationic tectons with other metal complexes bearing negatively charged terminal $\mathrm{N}$-atoms at their periphery have been also investigated. In particular, thiocyanatometallate $\left[\mathrm{M}(\mathrm{SCN})_{4}\right]^{2-}(\mathrm{M}=\mathrm{Pd}$ or $\mathrm{Hg}$ ) and isothiocyanatometallates $\left[\mathrm{Cu}(\mathrm{NCS})_{4}\right]^{2-}$ have been used. When combined with $2-2 \mathrm{H}^{+}$dication, different molecular networks based on ${ }^{+} \mathrm{N}-\mathrm{H} \cdots \mathrm{N}^{-}$or ${ }^{+} \mathrm{N}-\mathrm{H} \cdots \mathrm{S}^{-}$type of interaction patterns have been obtained [47]. The dimensionality of the networks depends on the orientation of the lone pairs of the anionic moieties. Thus, $1 \mathrm{D}$ architectures with $\left[\mathrm{M}(\mathrm{SCN})_{4}\right]^{2-}(\mathrm{M}=\mathrm{Pd}$ or $\mathrm{Hg})$ and 2D networks with $\left[\mathrm{Cu}(\mathrm{NCS})_{4}\right]^{2-}$ have been generated (Figure 7.12).

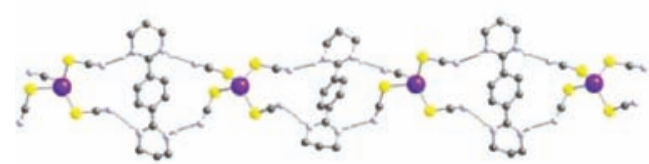

(a)

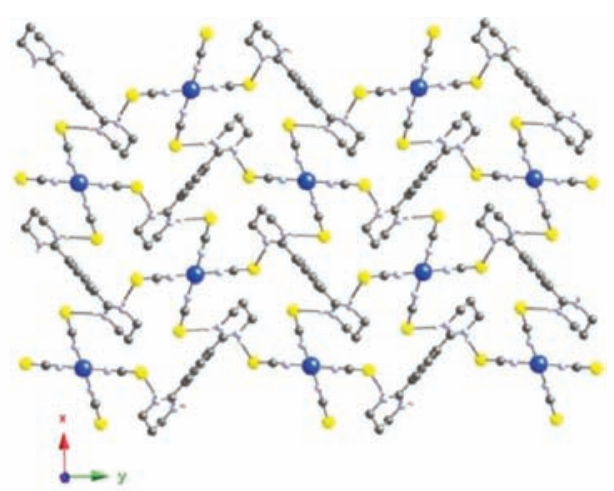

(b)

Figure 7.12 (a) 1D CAHB network formed when $2-2 \mathrm{H}^{+}$was combined with $\left[\mathrm{M}(\mathrm{SCN})_{4}\right]^{2-}(\mathrm{M}=\mathrm{Pd}$ or $\mathrm{Hg}$ ). (b) $2 \mathrm{D}$ CAHB network formed between $2-2 \mathrm{H}^{+}$and $\left[\mathrm{Cu}(\mathrm{NCS})_{4}\right]^{2-}$. 
Using ${ }^{+} \mathrm{N}-\mathrm{H} \cdots \mathrm{X}^{-}$-type interactions, the formation of $\mathrm{H}$-bonded networks was demonstrated by combining other metallatectons such as halogenometallates and bisamidinium-type tectons. These architectures are not discussed here.

The use of cyanometallate anions in conjunction with a variety of dicationic bisamidinium-type tectons has generated a massive collection of networks and properties. The following sections will extensively discuss the obtained results.

\subsubsection{Polycyanometallate as H-Bond Acceptor}

Due to their tunability and stability, cyanometallate anions are interesting H-bond acceptor tectons. Indeed, this class of compounds offers a large variety of charge $(-1$, $-2,-3,-4$ ) and geometry (linear, square planar, octahedral) around the metal center. Among the stable metal cyanide complexes, those shown in Figure 7.13 have been used as building blocks for the formation of hybrid molecular networks in the presence of organic dicationic tectons. It is worth noting that with respect to the localization of the protons, owing to the difference in $\mathrm{pKa}$ values between cyanometallates $\left[\mathrm{M}^{\mathrm{I}}(\mathrm{CN})_{2}\right]^{-}(\mathrm{M}=\mathrm{Ag}$ and $\mathrm{Au}),\left[\mathrm{M}^{\mathrm{II}}(\mathrm{CN})_{4}\right]^{2-}(\mathrm{M}=\mathrm{Ni}, \mathrm{Pd}$, and $\mathrm{Pt})$, $\left[\mathrm{Fe}^{\mathrm{II}}(\mathrm{CN})_{5} \mathrm{NO}\right]^{2-},\left[\mathrm{M}^{\mathrm{III}}(\mathrm{CN})_{6}\right]^{3-}(\mathrm{M}=\mathrm{Fe}, \mathrm{Co}$, and $\mathrm{Cr})$, and $\left[\mathrm{M}^{\mathrm{II}}(\mathrm{CN})_{6}\right]^{4-}(\mathrm{M}=\mathrm{Fe}$ and $\mathrm{Ru}$ ) anions (Figure 7.13) and unprotonated bisamidines, the acidic protons should be localized on the nitrogen atoms of bisamidinium cations, leading to a reliable ${ }^{+} \mathrm{N}-\mathrm{H} \cdots \mathrm{N}^{-}$recognition patterns.

The $\mathrm{N}-\mathrm{N}$ distances in cyanometallates are in the range of 3.9-4.7 $\AA$ for $\left[\mathrm{M}^{\mathrm{II}}(\mathrm{CN})_{4}\right]^{2-},\left[\mathrm{Fe}^{\mathrm{II}}(\mathrm{CN})_{5} \mathrm{NO}\right]^{2-},\left[\mathrm{M}^{\mathrm{III}}(\mathrm{CN})_{6}\right]^{3-}$, and $\left[\mathrm{M}^{\mathrm{II}}(\mathrm{CN})_{6}\right]^{4-}$, which impose a rather long distance between the two amidinium moieties if a dihapto mode of $\mathrm{H}$ bonding is desired. This may be achieved by using the phenyl group as a spacer (compound $2-2 \mathrm{H}^{+}$, Figure 7.14). For $\left[\mathrm{M}^{\mathrm{I}}(\mathrm{CN})_{2}\right]^{-}$, the N-N distances is in the range of 6.2-6.6 $\AA$. However, for this type of anion, the formation of extended networks, instead of a dihapto mode of H-bonding, requires monohapto modes of connectivity.

In the following, the formation of molecular networks will be discussed based on (i) the stoichiometry between organic and inorganic tectons; (ii) the metrics and the

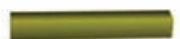

$\left[\mathbf{M}^{1}(\mathbf{C N})_{2}\right]^{*}(\mathbf{M}=\mathbf{A g}, \mathbf{A u})$

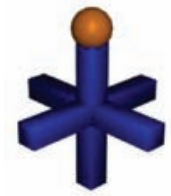

$\left[\mathrm{Fe}^{\mathrm{II}}(\mathrm{CN})_{5} \mathrm{NO}\right]^{2-}$

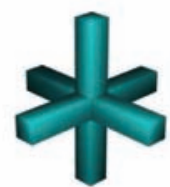

$\left[\mathrm{M}^{\mathrm{II}}(\mathrm{CN})_{6}\right]^{4}(\mathrm{M}=\mathrm{Fe}, \mathrm{Ru})$

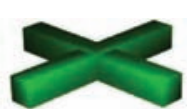

$\left[\mathrm{M}^{\mathrm{II}}(\mathrm{CN})_{4}\right]^{2 \cdot}(\mathrm{M}=\mathrm{Ni}, \mathrm{Pd}, \mathrm{Pt})$

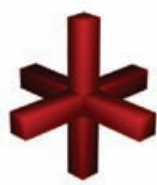

$\left[\mathrm{M}^{\mathrm{III}}(\mathrm{CN})_{6}\right]^{3 .}(\mathrm{M}=\mathrm{Co}, \mathrm{Cr}, \mathrm{Fe})$

Figure 7.13 Schematic representation of the polycyanometallate acting as $\mathrm{H}$-bond acceptors. 


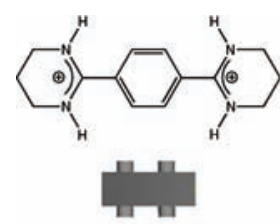

$2-2 \mathrm{H}^{+}$

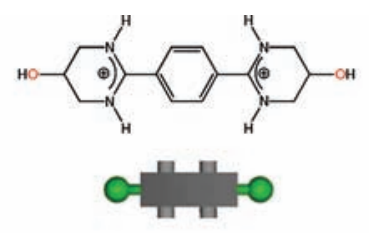

$3-2 \mathrm{H}^{+}$
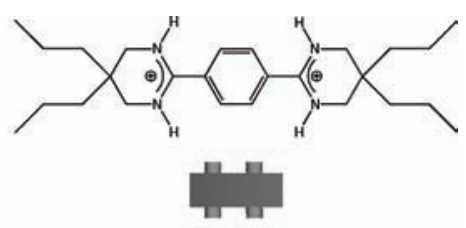

$4-2 \mathrm{H}^{+}$

Figure 7.14 Bisamidinium cations $2-2 \mathrm{H}^{+}, 3-2 \mathrm{H}^{+}$, and $4-2 \mathrm{H}^{+}$used for the formation of CAHB networks when combined with cyanometallates.

geometry around the metal center and the geometry of the organic tecton, and (iii) the influence of the nature of cations as well as of solvent molecules on the packing of networks and the formation of crystalline materials.

\section{4}

\section{Charge-Assisted H-Bonded Networks Based on Amidinium and Polycyanometallate Tectons}

Here, we shall focus on the three most illustrative bisamidinium cations $\mathbf{X}-2 \mathrm{H}^{+}$ $(\mathrm{X}=2-4)$ (Figure 7.14). Results obtained with many other bisamidinium-based tectons will not be presented. Owing to the presence of the phenyl group as spacer connecting the two cyclic amidinium moieties, these tectons $\mathrm{X}-2 \mathrm{H}^{+}(\mathrm{X}=2-4)$ are not only stable toward hydrolysis but, because of the imposed distance between two acidic $\mathrm{H}$-atoms on each face of the tecton, they also interact with tetra- and hexacyanometallate anions through a dihapto mode of H-bonding.

All networks presented below are air stable and have been studied in the crystalline state using X-ray diffraction on single crystals.

\subsection{1}

\section{Octahedral Cyanometallate Anions}

\subsubsection{1 $\left[\mathrm{M}^{\prime \prime \prime \prime}(\mathrm{CN})_{6}\right]^{3-}$ and $2-2 \mathrm{H}^{+}$or $3-2 \mathrm{H}^{+}(\mathrm{M}=\mathrm{Fe}, \mathrm{Co}$, and $\mathrm{Cr})$}

For charge neutrality reasons, the combination of dicationic tectons $2-2 \mathrm{H}$ and $3-2 \mathrm{H}$ with $\left[\mathrm{M}^{\mathrm{III}}(\mathrm{CN})_{6}\right]^{3-}(\mathrm{M}=\mathrm{Fe}, \mathrm{Co}$, and $\mathrm{Cr})$ should lead to crystals of general formula $(\mathrm{X}$ $\left.2 \mathrm{H}^{+}\right)_{3}\left(\left[\mathrm{M}^{\mathrm{III}}(\mathrm{CN})_{6}\right]^{3-}\right)_{2}(\mathrm{X}=2$ or 3$)$. Because of the dihapto or chelate mode of $\mathrm{H}$ bonding between $\mathrm{X}-2 \mathrm{H}^{+}$and the octahedral $\left[\mathrm{M}^{\mathrm{III}}(\mathrm{CN})_{6}\right]^{3-}$ anion, a supramolecular chirality taking place within the second coordination sphere around the metal is expected (Figure 7.15). Indeed, by analogy with $\Delta$ and $\Lambda$ type of chirality defined for octahedral complexes surrounded by two or three bidentate chelating ligands, within the second coordination sphere, the formation of a chelate through a dihapto mode of H-bonding between the dicationic tecton $\mathrm{X}-2 \mathrm{H}^{+}$and $\left[\mathrm{M}^{\mathrm{III}}(\mathrm{CN})_{6}\right]^{3-}$ generates the chirality of the $\Delta^{\prime}$ and $\Lambda^{\prime}$ type. This type of chirality, although based on H-bonding chelates, may be seen as analogous to the trisoxalatometallate-extended architectures [48]. 


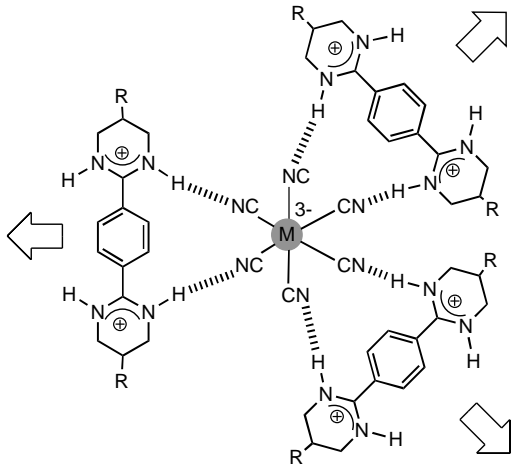

$\Delta^{\prime}$

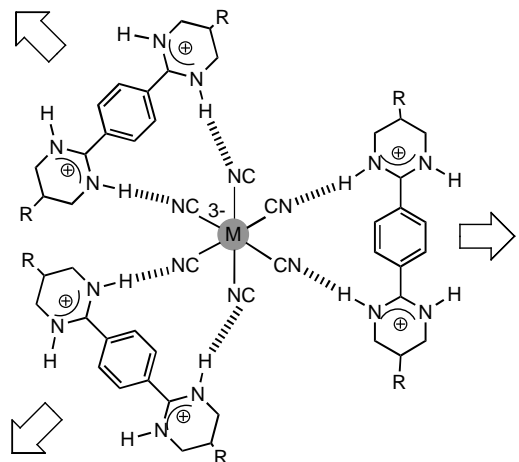

$\Delta^{\prime}$

Figure 7.15 Schematic representation of supramolecular chirality of the $\Delta^{\prime}$ and $\Lambda^{\prime}$ type obtained upon binding within the second coordination sphere of octahedral $\left[\mathrm{M}^{\prime \prime \prime}(\mathrm{CN})_{6}\right]^{3-}$ anion by dicationic $\mathbf{X}-2 \mathrm{H}^{+}$during the formation of $\left(\mathbf{X}-2 \mathrm{H}^{+}\right)_{3}\left(\left[\mathrm{M}^{\text {III }}(\mathrm{CN})_{6}\right]^{3-}\right)_{2}$ networks $(\mathbf{X}=2$ or 3$)$.

The 2D honeycomb-type neutral 2D charge-assisted H-bonded networks formed upon combining the cationic organic tecton with $\left[\mathrm{M}^{\mathrm{III}}(\mathrm{CN})_{6}\right]^{3-}(\mathrm{M}=\mathrm{Co}, \mathrm{Cr}$, and $\mathrm{Fe})$ present deformed hexagonal cavities [49]. The crystal is composed of dications $\mathrm{X}-2 \mathrm{H}^{+}$, two $\left[\mathrm{M}^{\mathrm{III}}(\mathrm{CN})_{6}\right]^{3-}$ dianions, and water molecules (Figure 7.16). The 2D networks are formed by interconnection of dicationic and dianionic units through dihapto mode of H-bonding ( $\mathrm{N} \cdot \mathrm{N}$ distance varying between 2.8 and $3.0 \AA$ A). The connectivity mode and the stoichiometry ( $3 / 2)$ between cations and anions lead to the generation of deformed hexagonal channels filled with seven water molecules in the case of $\left(2-2 \mathrm{H}^{+}\right)_{3}\left(\left[\mathrm{M}^{\mathrm{III}}(\mathrm{CN})_{6}\right]^{3-}\right)_{2}(\mathrm{M}=\mathrm{Fe}$ and $\mathrm{Co})$, six water molecules in the case of $\left(2-2 \mathrm{H}^{+}\right)_{3}\left(\left[\mathrm{Cr}^{\mathrm{III}}(\mathrm{CN})_{6}\right]^{3-}\right)_{2}$, and eight water molecules in the case of (3$\left.2 \mathrm{H}^{+}\right)_{3}\left(\left[\mathrm{M}^{\mathrm{III}}(\mathrm{CN})_{6}\right]\right)_{2}(\mathrm{M}=\mathrm{Fe}, \mathrm{Cr}$, and $\mathrm{Co})$ (Figure 7.17). The water molecules form H-bonded networks parallel to the axis of the channels. Due to the presence of

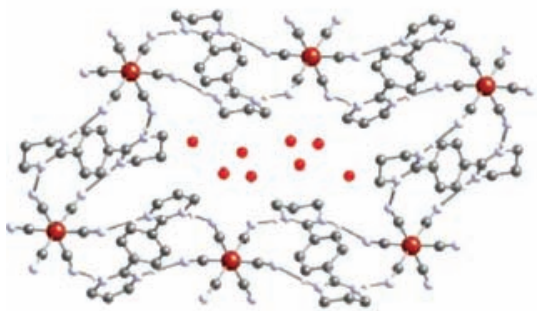

(a)

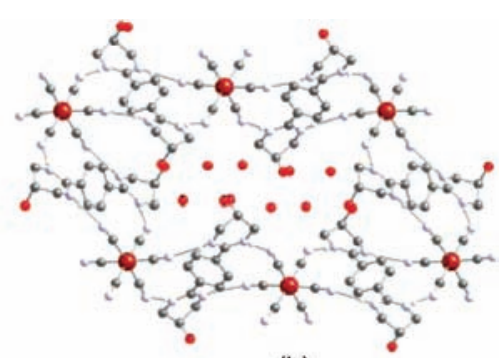

(b)

of water molecules and a view of the $\mathrm{H}$-bonded water polymer: (a) with $\left(2-2 \mathrm{H}^{+}\right)$and (b) with $\left(3-2 \mathrm{H}^{+}\right)$. $\mathrm{H}$-atoms are omitted for clarity.
Figure 7.16 Portions of the X-ray structure of $\left(\mathrm{X}-2 \mathrm{H}^{+}\right)_{3}\left(\left[\mathrm{M}^{\prime \prime \prime}(\mathrm{CN})_{6}\right]^{3-}\right)_{2}$ showing the alternate positioning of $\Delta^{\prime}$ and $\Lambda^{\prime}$ supramolecular enantiomers and the inclusion 


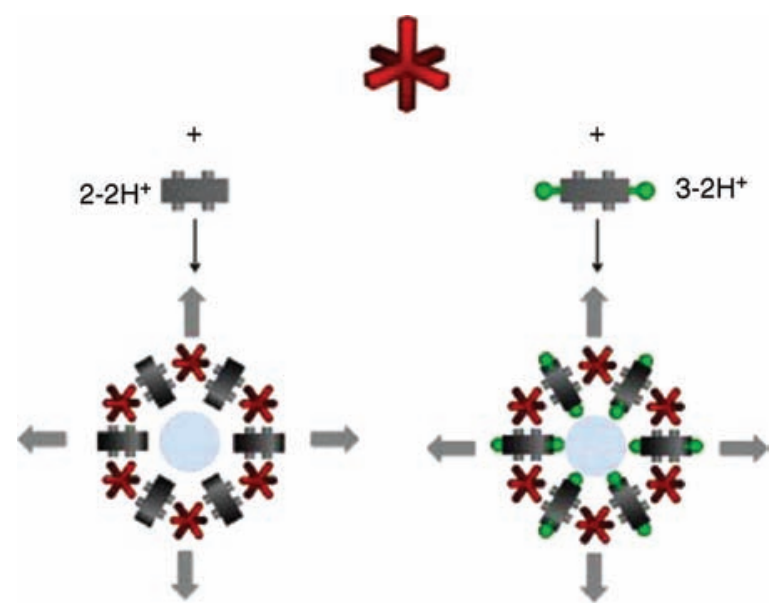

Figure 7.17 Schematic representation of the 2D H-bonded network formed upon self-assembly of the dicationic $\mathrm{X}-2 \mathrm{H}^{+}(\mathrm{X}=\mathbf{2}$ or $\mathbf{3})$ with $\left[\mathrm{M}^{\prime \prime \prime}(\mathrm{CN})_{6}\right]^{3-}(\mathrm{M}=\mathrm{Fe}, \mathrm{Cr}$, or $\mathrm{Co})$.

additional H-bond donors in the case of $\left(3-2 \mathrm{H}^{+}\right)_{3}\left(\left[\mathrm{M}^{\mathrm{III}}(\mathrm{CN})_{6}\right]\right)$, a strong $\mathrm{H}$-bonded network is formed between hydroxyl groups and the water molecules.

\subsubsection{2 $\left[\mathrm{M}^{\text {III }}(\mathrm{CN})_{6}\right]^{3-}$ and $4-2 \mathrm{H}^{+}(\mathrm{M}=\mathrm{Fe}, \mathrm{Co}$, and $\mathrm{Cr})$}

When $4-2 \mathrm{H}^{+}$is combined with $\left[\mathrm{M}^{\mathrm{III}}(\mathrm{CN})_{6}\right]^{3-}(\mathrm{M}=\mathrm{Fe}, \mathrm{Co}$, and $\mathrm{Cr})$, the resulting network has the same connectivity as those observed for $\left(\mathrm{X}-2 \mathrm{H}^{+}\right)_{3}\left(\left[\mathrm{M}^{\mathrm{III}}(\mathrm{CN})_{6}\right]^{3-}\right)_{2}$ ( $\mathrm{X}=\mathbf{2}$ or 3 ) (isostructural crystals) [50]. Interestingly, in this case, the hexagons are not deformed and no solvent molecules are present in the crystal. The water molecules present in previously discussed crystals based on tectons $\left(2-2 \mathrm{H}^{+}\right)$and $\left(3-2 \mathrm{H}^{+}\right)$are replaced by alkyl chains of the organic tecton $\left(4-2 \mathrm{H}^{+}\right)$(Figure 7.18).

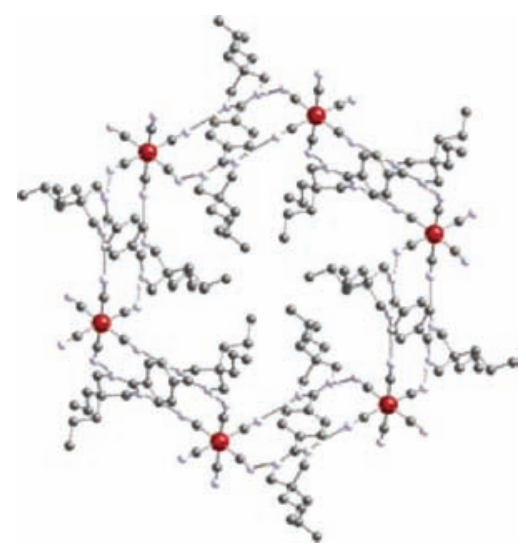

Figure 7.18 A portion of the X-ray structure of $\left(4-2 \mathrm{H}^{+}\right)_{3}\left(\left[\mathrm{M}^{\prime \prime \prime}(\mathrm{CN})_{6}\right]^{3-}\right)_{2}(\mathrm{M}=\mathrm{Fe}, \mathrm{Co}$, or $\mathrm{Cr})$. 


\subsubsection{3 $\left[\mathrm{M}^{\prime \prime}(\mathrm{CN})_{6}\right]^{4-}$ with $2-2 \mathrm{H}^{+}$or $4-2 \mathrm{H}^{+}(\mathrm{M}=\mathrm{Fe}$ and $\mathrm{Ru})$}

Dealing with octahedral $\left[\mathrm{M}^{\mathrm{II}}(\mathrm{CN})_{6}\right]^{4-}$ anionic complexes, again based on charge neutrality, for combinations of $2-2 \mathrm{H}^{+}$or $4-2 \mathrm{H}^{+}$with $\mathrm{Li}_{4}\left[\mathrm{M}^{\mathrm{II}}(\mathrm{CN})_{6}\right]$ and $\left(\mathrm{NH}_{4}\right)_{4}$ $\left[\mathrm{M}^{\mathrm{II}}(\mathrm{CN})_{6}\right]$ salts, crystals of formula $\left(\mathrm{X}-2 \mathrm{H}^{+}\right)_{2}\left(\left[\mathrm{M}^{\mathrm{II}}(\mathrm{CN})_{6}\right]^{4-}\right)(\mathrm{X}=\mathbf{2}$ or 4$)$ are obtained [51]. The recognition pattern between anion and cation is rather different when compared to the previous cases discussed above. The crystal is composed of two $2-2 \mathrm{H}^{+}$(or $\left.4-2 \mathrm{H}^{+}\right)$dications, one $\left[\mathrm{M}^{\mathrm{II}}(\mathrm{CN})_{6}\right]^{4-}(\mathrm{M}=\mathrm{Fe}$ or $\mathrm{Ru})$ anion, and eight $\mathrm{H}_{2} \mathrm{O}$ molecules. Each $\left[\mathrm{M}^{\mathrm{II}}(\mathrm{CN})_{6}\right]^{4-}(\mathrm{M}=\mathrm{Fe}$ or $\mathrm{Ru})$ complex is surrounded by four bisamidinium $2-2 \mathrm{H}^{+}$. For both cases, a neutral 2D network is obtained. The latter results from the interconnection of $1 \mathrm{D}$ networks, formed by H-bonds in a dihapto mode between two organic cations and four cyanide groups located at the square base of the octahedron, by a transversal organic tectons interacting through a bismonohapto mode of $\mathrm{H}$-bonding with the remaining two cyanides occupying the apical positions (Figures 7.19 and 7.20). The remaining two $\mathrm{H}$-bond donor $\mathrm{N}-\mathrm{H}$ sites of the transversal organic tectons are hydrogen bonded to water molecules. For both cases, the water molecules form branched hexagons composed of eight solvent molecules, which are located between 2D networks.

\subsubsection{4 $\left[\mathrm{M}^{\prime \prime}(\mathrm{CN})_{6}\right]^{4-}$ with $3-2 \mathrm{H}^{+}(\mathrm{M}=\mathrm{Fe}$ and $\mathrm{Ru})$}

Surprisingly, the connectivity mode for the combination of $\left[\mathrm{M}^{\mathrm{II}}(\mathrm{CN})_{6}\right]^{4-}(\mathrm{M}=\mathrm{Fe}$ or $\mathrm{Ru}$ ) with $3-2 \mathrm{H}^{+}$is different from the one of $\left(2-2 \mathrm{H}^{+}\right)_{2}\left(\left[\mathrm{M}^{\mathrm{II}}(\mathrm{CN})_{6}\right]^{4-}\right)$. In this case, as expected, although the formula is $\left(3-2 \mathrm{H}^{+}\right)_{2}\left(\left[\mathrm{M}^{\mathrm{II}}(\mathrm{CN})_{6}\right]\right)(\mathrm{M}=\mathrm{Fe}$ or $\mathrm{Ru})$, the recognition pattern leads to a $1 \mathrm{D}$ architecture. Each metallic anion is surrounded, in its square base, by two organic tectons with a dihapto mode of recognition on one side and a monohapto mode on the other face with the apical cyanide of an adjacent $\left[\mathrm{M}^{\mathrm{II}}(\mathrm{CN})_{6}\right]^{4-}$ anion (Figure 7.21 ). This connectivity mode leads to a $1 \mathrm{D}$ system for

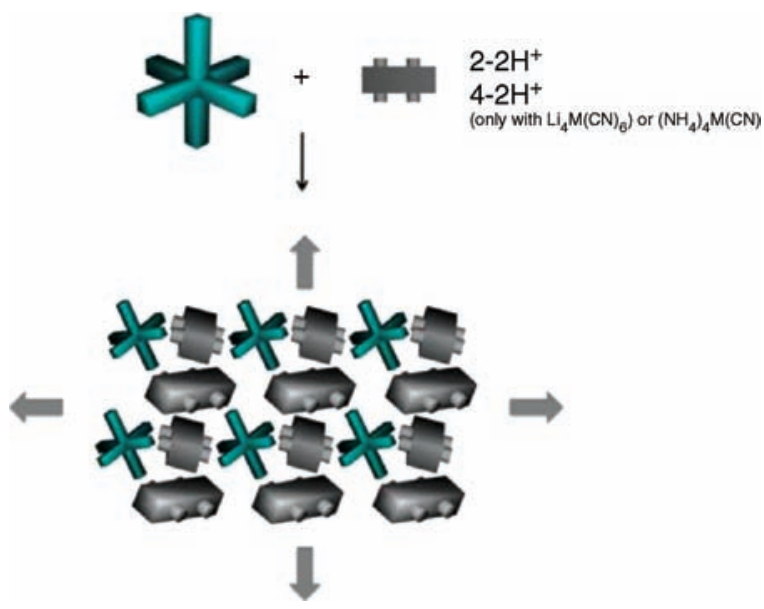

Figure 7.19 Schematic representation of a $2 \mathrm{D}$ network formed between octahedral $\left[\mathrm{M}^{\prime \prime}(\mathrm{CN})_{6}\right]^{4-}$ $(\mathrm{M}=\mathrm{Fe}$ or $\mathrm{Ru})$ anionic complexes and dicationic tectons $\left(\mathbf{X}-2 \mathrm{H}^{+}, \mathbf{X}=\mathbf{2}\right.$ or $\left.\mathbf{4}\right)$. 


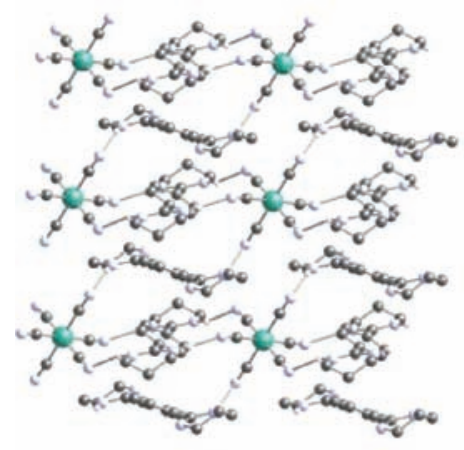

(a)

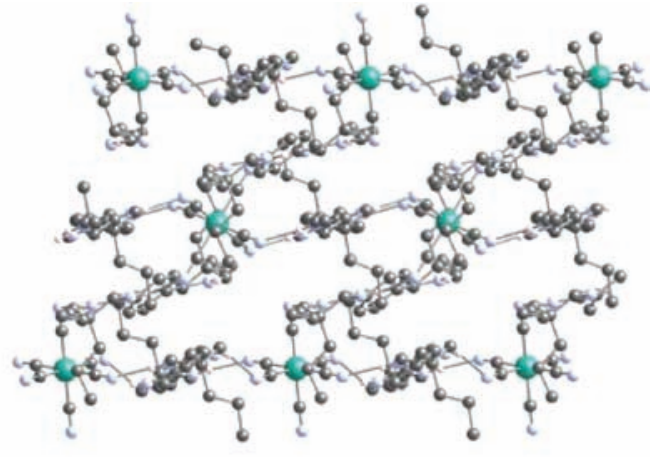

(b)

Figure 7.20 Portions of the $\mathrm{X}$-ray structure of $2 \mathrm{D} \mathrm{H}$-bonded network $\left(\mathrm{X}-2 \mathrm{H}^{+}\right)_{2}\left(\left[\mathrm{M}^{\prime \prime}(\mathrm{CN})_{6}\right]^{4-}\right)$ $(\mathrm{X}=\mathbf{2}$ or $\mathbf{4})$. The $2 \mathrm{D}$ network is formed through the interconnection of anionic 1D networks by $\mathrm{X}-2 \mathrm{H}^{+}$through a monohapto mode of

$\mathrm{H}$-bonding with the remaining two $\mathrm{CN}$ groups in axial positions of $\left[\mathrm{M}^{\prime \prime}(\mathrm{CN})_{6}\right]^{4-}$ : (a) with (2$\left.2 \mathrm{H}^{+}\right)$and (b) with $\left(4-2 \mathrm{H}^{+}\right)$. Water molecules are omitted for clarity.

which two cations are parallel with a distance of $4.8 \AA$ between their centroids. Each cation is H-bonded only to three cyanide groups. These 1D systems are also surrounded by water molecules (six per formula unit) with a strong hydrogen bond network between hydroxyl groups and water molecules.

\subsubsection{5 $\left[\mathrm{M}^{\prime \prime}(\mathrm{CN})_{6}\right]^{4-}$ with $4-2 \mathrm{H}^{+}(\mathrm{M}=\mathrm{Fe}$ and $\mathrm{Ru})$}

Interestingly, when $4-2 \mathrm{H}^{+}$is combined with other $\mathrm{X}_{4}\left[\mathrm{Fe}^{\mathrm{II}}(\mathrm{CN})_{6}\right]$ salts $(\mathrm{X}=\mathrm{K}, \mathrm{Na}, \mathrm{Rb}$, and $\mathrm{Cs})$, crystals of general formula $\mathrm{X}_{2}\left(4-2 \mathrm{H}^{+}\right)_{3}\left(\left[\mathrm{Fe}^{\mathrm{II}}(\mathrm{CN})_{6}\right]^{4-}\right)_{2}(3 / 2$ stoichiometry) are obtained instead of the expected $2 / 1$ stoichiometry $\left(\left(4-2 \mathrm{H}^{+}\right)_{2}\left(\left[\mathrm{Fe}^{\mathrm{II}}(\mathrm{CN})_{6}\right]^{4-}\right)\right)[52]$. These crystals are isostructural to $\left(4-2 \mathrm{H}^{+}\right)_{3}\left(\left[\mathrm{M}^{\mathrm{III}}(\mathrm{CN})_{6}\right]^{3-}\right)_{2}$ (see Section 7.4.1.2) with the same recognition pattern between cations and anions. The alkali cations occupy a site located between the $\left[\mathrm{Fe}^{\mathrm{II}}(\mathrm{CN})_{6}\right]^{4-}$ anions, forming a 1D array parallel to the $c$-axis, with short $\mathrm{C} \equiv \mathrm{N}-\mathrm{X}$ distances (Figure 7.22, right). The increase in the $c$ parameter from $6.95 \AA$ for $\mathrm{Na}^{+}$to $8.37 \AA$ for $\mathrm{Cs}^{+}$is accompanied by a less pronounced decrease

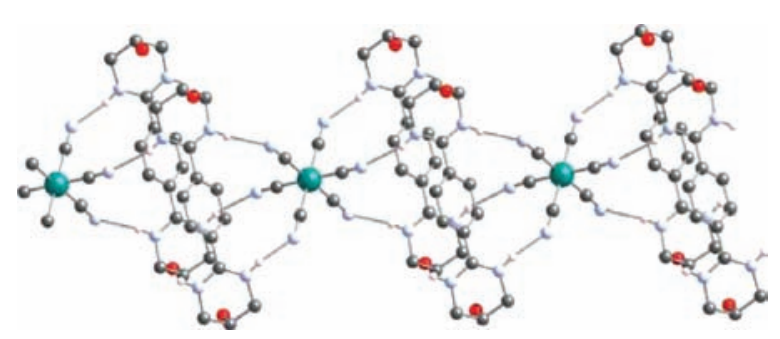

Figure 7.21 A portion of the X-ray structure of 1D H-bonded network $\left(3-2 \mathrm{H}^{+}\right)_{2}\left(\left[\mathrm{M}^{\prime \prime}(\mathrm{CN})_{6}\right]^{4-}\right)$ $(\mathrm{M}=\mathrm{Fe}$ or $\mathrm{Ru})$. 
210 7 Molecular Tectonics: Design of Hybrid Networks

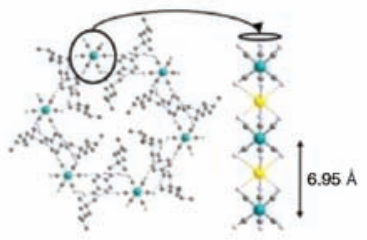

(a) $\mathrm{X}=\mathrm{Na}$

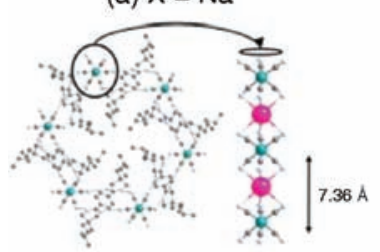

(c) $\mathrm{X}=\mathrm{Rb}$

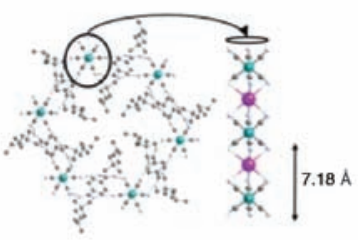

(b) $\mathrm{X}=\mathrm{K}$

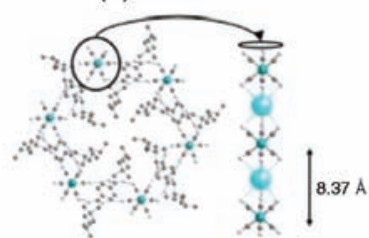

(d) $\mathrm{X}=C \mathrm{~s}$
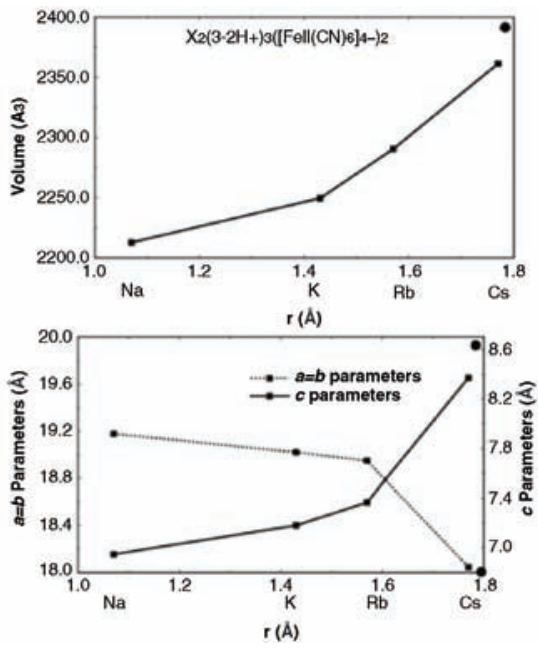

volume (ii) for $\mathrm{X}_{2}\left(4-2 \mathrm{H}^{+}\right)_{3}\left(\left[\mathrm{Fe}^{\prime \prime}(\mathrm{CN})_{6}\right]^{4-}\right)_{2}$ $(\mathrm{X}=\mathrm{Na}, \mathrm{K}, \mathrm{Rb}$, and $\mathrm{Cs})(\mathrm{v})$. The same parameters for $\left(4-2 \mathrm{H}^{+}\right)_{3}\left(\left[\mathrm{Fe}^{\mathrm{III}}(\mathrm{CN})_{6}\right]^{3-}\right)_{2}(\lambda)$ are also given for the sake of comparison.

(a), K (b), Rb (c), and Cs (d)). Right: Plots of the variation of the cell parameters (i) and cell

of $a, b$ parameters, as shown in Figure 7.22, left. The volume of the cell is enhanced by increasing the radii of the inserted alkali cation. It is worth noting that for $\mathrm{Cs}_{2}(4-$ $\left.2 \mathrm{H}^{+}\right)_{3}\left(\left[\mathrm{Fe}^{\mathrm{II}}(\mathrm{CN})_{6}\right]^{4-}\right)_{2}$, the obtained metrics are the closest ones to those observed for $\left(4-2 \mathrm{H}^{+}\right)_{3}\left(\left[\mathrm{Fe}^{\mathrm{III}}(\mathrm{CN})_{6}\right]^{3-}\right)_{2}$.

\subsection{2}

\section{Pentadentate Cyanometallate Anions, $\left[\mathrm{Fe}^{\prime \prime}(\mathrm{CN})_{5} \mathrm{NO}^{2-}\right.$ and $2-2 \mathrm{H}^{+}$}

By analogy with $\left[\mathrm{M}^{\mathrm{III}}(\mathrm{CN})_{6}\right]^{3-}$ anions (Section 7.4.1.1), octahedral nitroprussiate $\left[\mathrm{Fe}^{\mathrm{II}}(\mathrm{CN})_{5} \mathrm{NO}\right]^{2-}$ is an interesting anionic tecton allowing to study several issues related to supramolecular chirality, that is, chirality taking place within the second coordination sphere around the metal center. Due to the presence of five $\mathrm{CN}^{-}$groups in $\left[\mathrm{Fe}^{\mathrm{II}}(\mathrm{CN})_{5} \mathrm{NO}\right]^{2-}$, which may be engaged in $\mathrm{H}$-bond patterns, the formation of achiral or chiral architectures may be envisaged. Indeed, if the dihapto mode of $\mathrm{H}$ bonding of two bisamidinium moieties occurs in the basal plane of $\left[\mathrm{Fe}^{\mathrm{II}}(\mathrm{CN})_{5} \mathrm{NO}\right]^{2-}$ (Figure 7.23, top), no chirality may be expected (presence of a plane of symmetry). However, for the other possibility, a chiral architecture may be formed (Figure 7.23, bottom).

The combination of $\left[\mathrm{Fe}^{\mathrm{II}}(\mathrm{CN})_{5} \mathrm{NO}\right]^{2-}$ with $2-2 \mathrm{H}^{+}$leads to a neutral 1D network of formula $\left(2-2 \mathrm{H}^{+}\right)\left(\left[\mathrm{Fe}^{\mathrm{II}}(\mathrm{CN})_{5} \mathrm{NO}\right]^{2-}\right)$ resulting from interconnection of the anionic units by the tecton $2-2 \mathrm{H}^{+}$through a dihapto mode of $\mathrm{H}$-bonding [53]. The chelate mode of $\mathrm{H}$-bonding takes place on both sides of the tecton $2-2 \mathrm{H}^{+}$with two $\mathrm{CN}^{-}$units 

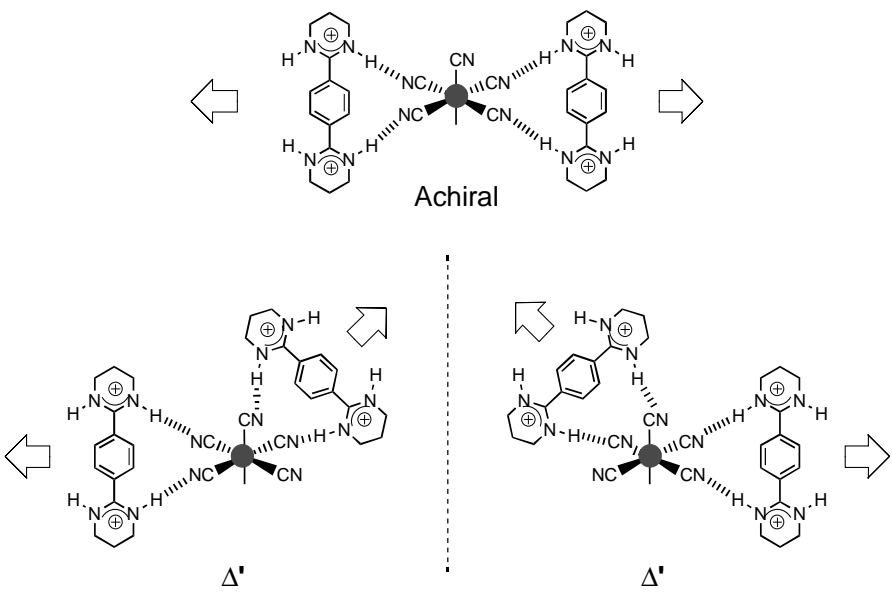

Figure 7.23 Schematic representation of the octahedral complex $\left[\mathrm{Fe}^{\prime \prime}(\mathrm{CN})_{5} \mathrm{NO}\right]^{2-}$ and its double chelation by the dicationic tectons 2 $2 \mathrm{H}^{+}$through a dihapto mode of $\mathrm{H}$-bonding either with two adjacent cyanides within the square base or with one $\mathrm{CN}^{-}$anion located within the square base and the other occupying an apical position leading thus to supramolecular chirality of the $\Delta^{\prime}$ and $\Lambda^{\prime}$ type.

located at the square base of the octahedron leading thus to an achiral unit. Within each neutral 1D networks, the NO units are disposed in an alternate fashion, with an unusual short $d_{\mathrm{O}-\mathrm{O}}$ distance of about $2.71 \AA$ A between NO groups facing each other in consecutive networks. The packing of the 1D networks in space, leading to the formation of the solid, generates channels, which are filled with water molecules forming polymeric chains (Figure 7.24).

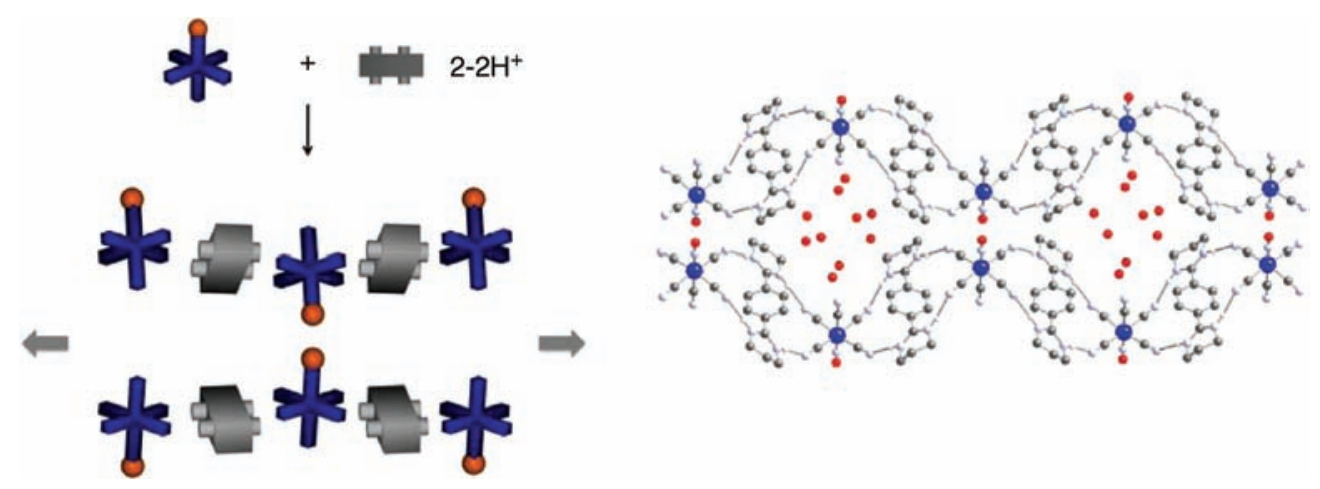

Figure 7.24 Left: Schematic representation of the 1D H-bonded achiral network formed upon selfassembly of the dicationic $2-2 \mathrm{H}^{+}$and $\left[\mathrm{Fe}^{\mathrm{II}}(\mathrm{CN}){ }_{5} \mathrm{NO}\right]^{2-}$. Right: A portion of the X-ray structure of (2$\left.2 \mathrm{H}^{+}\right)\left(\left[\mathrm{Fe}^{\prime \prime}(\mathrm{CN})_{5} \mathrm{NO}\right]^{2-}\right)$. 
212 7 Molecular Tectonics: Design of Hybrid Networks

\section{4 .3}

\section{Square Planar Cyanometallate Anions}

\subsubsection{1 $\left[\mathrm{M}^{\prime \prime}(\mathrm{CN})_{4}\right]^{2-}$ and $2-2 \mathrm{H}^{+}$or $4-2 \mathrm{H}^{+}(\mathrm{M}=\mathrm{Ni}, \mathrm{Pd}$, and $\mathrm{Pt})$}

Owing to the metric (distance between two acidic hydrogen atoms located on the same face of the tecton) and charge (dication) of the $\mathrm{X}-2 \mathrm{H}^{+}(\mathrm{X}=\mathbf{2}$ or 4$)$ for the combination of these two tectons with $\left[\mathrm{M}^{\mathrm{II}}(\mathrm{CN})_{4}\right]^{2-}(\mathrm{M}=\mathrm{Ni}$, Pd, or Pt) a $1 / 1$ stoichiometry and a dihapto mode of recognition may be expected. In other terms, for such a network, each dication $\mathrm{X}-2 \mathrm{H}^{+}$should be surrounded by two dianions and, conversely, each dianion $\left[\mathrm{M}^{\mathrm{II}}(\mathrm{CN})_{4}\right]^{2-}$ should be in interactions with two dications through a dihapto mode of $\mathrm{H}$-bonding.

The predicted networks were indeed observed for combinations of $2-2 \mathrm{H}^{+}$or 4$2 \mathrm{H}^{+},\left[\mathrm{M}^{\mathrm{II}}(\mathrm{CN})_{4}\right]^{2-}$ with $\mathrm{M}=\mathrm{Pd}, \mathrm{Pt}$, and $\mathrm{Ni}$ (crystals of general formula $\left(\mathrm{X}-2 \mathrm{H}^{+}\right.$) $\left(\left[\mathrm{M}^{\mathrm{II}}(\mathrm{CN})_{4}\right]^{2-}\right)(\mathrm{X}=\mathbf{2}$ or $4, \mathrm{M}=\mathrm{Ni}, \mathrm{Pd}$, and $\left.\mathrm{Pt})\right)[50,51]$. In all cases, X-ray diffraction on single crystals (Figure 7.25) revealed that all the crystalline materials are isostructural. The 1D networks, of general formula $\left(\mathrm{X}-2 \mathrm{H}^{+}\right)\left(\left[\mathrm{M}^{\mathrm{II}}(\mathrm{CN})_{4}\right]^{2-}\right)$, resulting from a dihapto mode of $\mathrm{H}$-bonding between $\mathrm{X}-2 \mathrm{H}^{+}$and the square anions, are packed in a parallel fashion in the crystal. The absence of solvent molecules in the lattice indicates that the cohesion of crystals is ensured by the two complementary components.

Interestingly, as expected by the design of cation $4-2 \mathrm{H}^{+}$, the presence of propyl chains controls the spacing between the 1D networks. Indeed, whereas for the 1D networks obtained with $\left[\mathrm{M}(\mathrm{CN})_{4}\right]^{2-}$ anions and $2-2 \mathrm{H}^{+}$, the distance between two consecutive networks in the yOz plane is the range of 6.40 and $6.44 \AA$, in the case of 4$2 \mathrm{H}^{+}$the spacing is increased and it ranges from $8.41 \AA$ for $\mathrm{Ni}$ to 8.28 and $8.26 \AA$ for $\mathrm{Pd}$ and Pt, respectively.

This example clearly illustrates the control of the packing of networks through the design of the organic tecton.

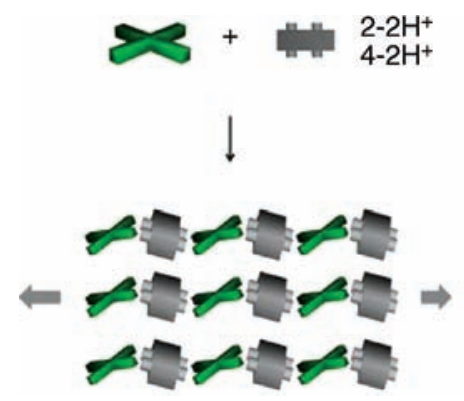

Figure 7.25 Left: Schematic representation of the 1D $\mathrm{H}$-bonded network formed upon selfassembly of the dicationic $\mathrm{X}-2 \mathrm{H}^{+}(\mathrm{X}=\mathbf{2}$ or 4$)$ and $\left[\mathrm{M}^{\prime \prime}(\mathrm{CN})_{6}\right]^{2-}(\mathrm{M}=\mathrm{Ni}, \mathrm{Pd}$, or $\mathrm{Pt})$ ensured by

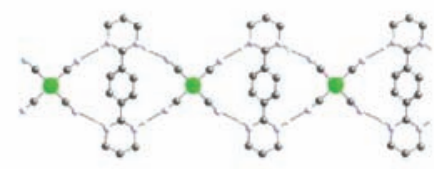

(a)

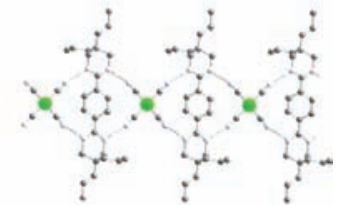

(b) strong $\mathrm{H}$-bonds through a dihapto mode of interaction. Right: Portions of the X-ray structure of (a) $\left(2-2 \mathrm{H}^{+}\right)\left(\left[\mathrm{M}^{\prime \prime}(\mathrm{CN})_{4}\right]^{2-}\right)$ and (b) $\left(4-2 \mathrm{H}^{+}\right)$ $\left(\left[\mathrm{M}^{\mathrm{II}}(\mathrm{CN})_{4}\right]^{2-}\right)(\mathrm{M}=\mathrm{Ni}, \mathrm{Pd}$, and $\mathrm{Pt})$. 


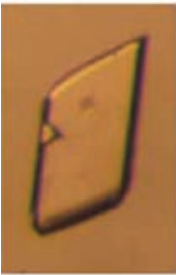

(a)

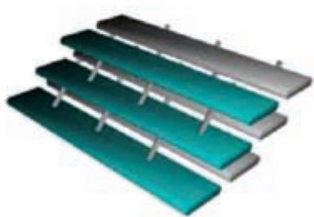

(b)

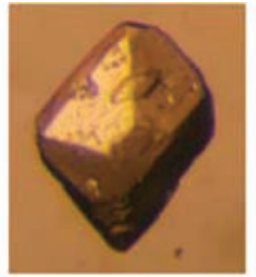

(c)

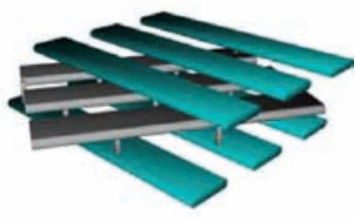

(d)

Figure 7.26 Pictures of (a) polymorph $\alpha$, obtained for the combination of tecton $3-2 \mathrm{H}^{+}$ with $\left[\mathrm{M}^{\prime \prime}(\mathrm{CN})_{4}\right]^{2-}(\mathrm{M}=\mathrm{Ni}, \mathrm{Pd}$, and Pt), and (c) polymorph $\beta$, obtained only for $\left(3-2 \mathrm{H}^{+}\right)$

$\left(\left[\mathrm{Pt}^{\prime \prime}(\mathrm{CN})_{4}\right]^{2-}\right)$. (b) and (d) represent schematically the arrangement of the networks in the $\alpha$ - and $\beta$-phases, respectively.

\subsubsection{2 $\left[\mathrm{M}^{\prime \prime}(\mathrm{CN})_{4}\right]^{2-}$ and $3-2 \mathrm{H}^{+}(\mathrm{M}=\mathrm{Ni}, \mathrm{Pd}$, and $\mathrm{Pt})$}

Since the organic tecton $3-2 \mathrm{H}^{+}$offers additional H-bond donor sites (overall six acidic hydrogen atoms), one may expect different types of connectivity with $\left[\mathrm{M}^{\mathrm{II}}(\mathrm{CN})_{4}\right]^{2-}$ anions [38f]. Indeed, the combination of $3-2 \mathrm{H}^{+}$with $\left[\mathrm{M}^{\mathrm{II}}(\mathrm{CN})_{4}\right]^{2-}$ leads to polymorphs, having the same formula $\left(3-2 \mathrm{H}^{+}\right)\left(\left[\mathrm{M}^{\mathrm{II}}(\mathrm{CN})_{4}\right]^{2-}\right)(\mathrm{M}=\mathrm{Ni}, \mathrm{Pd}$, and Pt) [54].

Whereas in the case of $\left[\mathrm{Ni}(\mathrm{CN})_{4}\right]^{2-}$ and $\left[\mathrm{Pd}(\mathrm{CN})_{4}\right]^{2-}$, plate shape crystals ( $\alpha$-phase) were obtained (Figure 7.26), for $\left[\mathrm{Pt}(\mathrm{CN})_{4}\right]^{2-}$, a mixture of plate ( $\alpha$-phase) and prismatic shape ( $\beta$-phase) (Figure 7.26) crystals were observed. For the $\alpha$-phase, the crystals are composed of $3-2 \mathrm{H}^{+}$dications and $\left[\mathrm{M}(\mathrm{CN})_{4}\right]^{2-}\left(\mathrm{M}=\mathrm{Ni}^{2+}, \mathrm{Pd}^{2+}\right.$, and $\mathrm{Pt}^{2+}$ ) dianions, forming as previously described for $2-2 \mathrm{H}^{+}$and $4-2 \mathrm{H}^{+}$cations, neutral 1D network through a dihapto mode of $\mathrm{H}$-bonding $\left(d_{\mathrm{N}-\mathrm{N}}\right.$ in the range of 2.83 and $2.90 \AA$ ) without any solvents molecules (Figure 7.27).

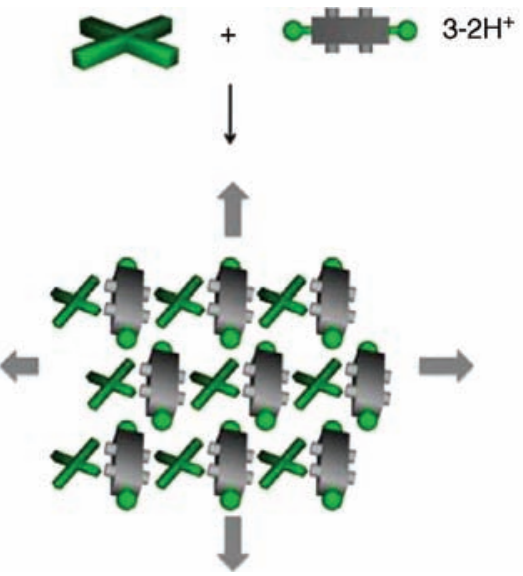

Figure 7.27 Left: Schematic representation of the 2D $\mathrm{H}$-bonded network formed upon selfassembly of the dicationic $3-2 \mathrm{H}^{+}$and $\left[\mathrm{M}^{\prime \prime}(\mathrm{CN})_{6}\right]^{2-}(\mathrm{M}=\mathrm{Ni}, \mathrm{Pd}$, or Pt $)$ ensured by

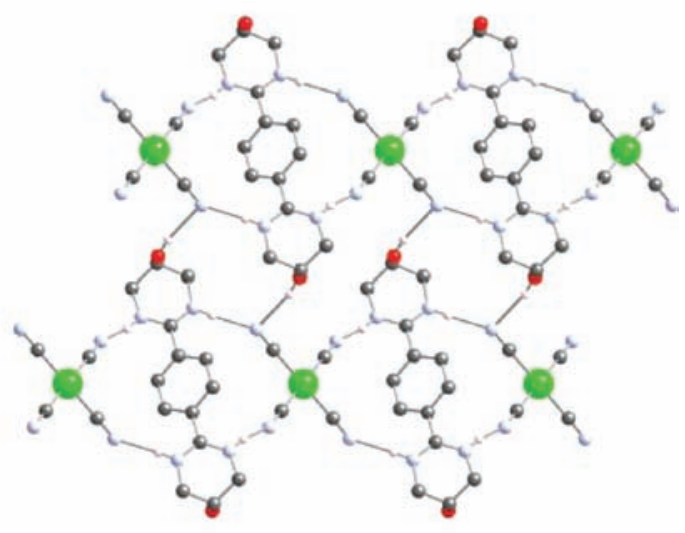

interconnection between the 1D arrays through $\mathrm{OH}$... O interactions. Right: A portion of the $\mathrm{X}$ ray structure of $\left(3-2 \mathrm{H}^{+}\right)\left(\left[\mathrm{M}^{\prime \prime}(\mathrm{CN})_{4}\right]^{2-}\right)$ $(\mathrm{M}=\mathrm{Ni}, \mathrm{Pd}$, and $\mathrm{Pt})$. 
Owing to the presence of hydroxyl groups within the backbone of the cations, the $\mathrm{OH}$ groups behave as secondary H-bond donor sites and the overall structure is a $2 \mathrm{D}$ network. The two $\mathrm{OH}$ groups in axial position interconnect the 1D networks, disposed in parallel fashion, through $\mathrm{H}$-bonds of the $\mathrm{OH}-\mathrm{N} \equiv \mathrm{C}$ type $\left(d_{\mathrm{N}-\mathrm{O}}\right.$ in the range of 2.95, and $2.98 \AA$ ). Among the four $\mathrm{CN}$ groups connected to the metal center, only two are involved in $\mathrm{H}$-bond with the $\mathrm{OH}$ groups (Figure 7.27). In the case of [Pt $\left.(\mathrm{CN})_{4}\right]^{2-}$, in addition to the $\alpha$-phase, another morphology ( $\beta$-phase) was observed (Figure 7.26). The difference with the $\alpha$-phase relies on the connection of the formed 1D arrays through $\mathrm{H}$-bonds. Here, the second type of $\mathrm{H}$-bond is of $\mathrm{OH}-\mathrm{O}$ type and takes place between $\mathrm{OH}$ moieties belonging to consecutive planes $\left(d_{\mathrm{OH}-\mathrm{O}}=2.88 \AA\right.$ ), leading to a tilt angle of about $60^{\circ}$ between two consecutive 1D arrays (Figure 7.26). Because of this particular orientation of consecutive layers, the overall architecture may be considered a 3D hydrogen-bonded network.

\subsection{4}

\section{Linear Cyanometallate Anions $\left[\mathrm{M}^{\prime}(\mathrm{CN})_{2}\right]^{-}(\mathrm{M}=\mathrm{Ag}$ and $\mathrm{Au})$}

Due to the linear geometry of the $\left[\mathrm{M}^{\mathrm{I}}(\mathrm{CN})_{2}\right]^{-}(\mathrm{M}=\mathrm{Ag}$ or $\mathrm{Au})$ anions and the rather long distance between the two $\mathrm{N}$-atoms of the cyano groups located at the extremities of the anion, the combination of such anions with bisamidinium cation should, in principle, lead to a tetrakis-monohapto mode of $\mathrm{H}$-bonding between the anion and the cation. The combination of $2-2 \mathrm{H}^{+}$with $\left[\mathrm{M}^{\mathrm{I}}(\mathrm{CN})_{2}\right]^{-}(\mathrm{M}=\mathrm{Ag}$ and $\mathrm{Au})$ leads to crystals exclusively composed of $2-2 \mathrm{H}^{+}$dication and $\left[\mathrm{M}^{\mathrm{I}}(\mathrm{CN})_{2}\right]^{-}(\mathrm{M}=\mathrm{Ag}$ and $\mathrm{Au})$ anion with a $\left(2-2 \mathrm{H}^{+}\right)\left(\left[\mathrm{M}^{\mathrm{I}}(\mathrm{CN})_{2}\right]^{-}{ }_{2}\right)$ stoichiometry [55]. Each face of the tecton $2-2 \mathrm{H}^{+}$ is connected to two $\left[\mathrm{M}^{\mathrm{I}}(\mathrm{CN})_{2}\right]^{-}$anions imposing thus a $\mathrm{Au}-\mathrm{Au}$ and $\mathrm{Ag}-\mathrm{Ag}$ distances of 3.33 and $3.37 \AA$, respectively. The connectivity pattern, resulting from strong $\mathrm{H}$ bonds between donor and acceptor sites as well as $\mathrm{d}^{10}-\mathrm{d}^{10}$ interactions is given in Figure 7.28. The same type of pattern is observed for $1-2 \mathrm{H}^{+}$and $4^{\prime}-2 \mathrm{H}^{+}$cation bearing hexyl chains in its periphery (Figure 7.28).

Other polymorphs with different connectivity between the tectons are also observed. They will not be discussed here.

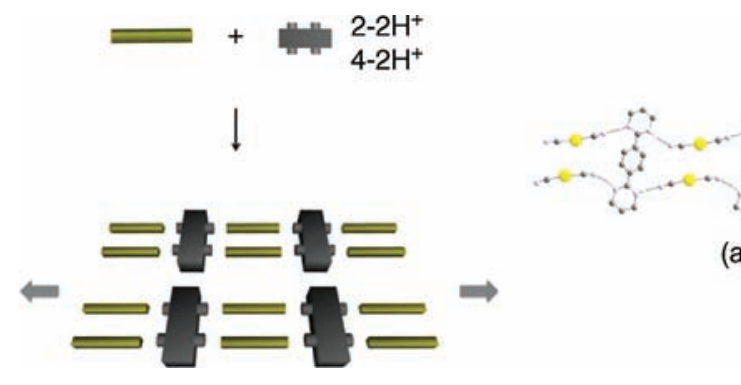

Figure 7.28 Left: Schematic representation of the 1D $\mathrm{H}$-bonded network formed upon selfassembly of the dicationic $\mathrm{X}-2 \mathrm{H}^{+}\left(\mathrm{X}=\mathbf{2}\right.$ or $\left.\mathbf{4}^{\prime}\right)$ and $\left[\mathrm{M}^{\prime}(\mathrm{CN})_{2}\right]^{-}(\mathrm{M}=\mathrm{Ag}$ or $\mathrm{Au})$. Right: Portions of the X-ray structure of (a) $\left(2-2 \mathrm{H}^{+}\right)$ $\left(\left[\mathrm{M}^{\prime}(\mathrm{CN})_{2}\right]^{-}\right)_{2}(\mathrm{M}=\mathrm{Ag}$ or $\mathrm{Au})$ and $(\mathrm{b})\left(4^{\prime}-2 \mathrm{H}^{+}\right)$ $\left(\left[\mathrm{M}^{\prime}(\mathrm{CN})\right]^{-}\right)_{2}(\mathrm{M}=\mathrm{Ag}$ or $\mathrm{Au})$. 


\section{5}

Properties of Charge-Assisted H-Bonded Networks Based on Amidinium Tectons

Exploiting specific properties resulting from the interconnection of tectons into networks and the packing of these periodic architectures into crystals is a matter of current interest [56]. In the following section, the solid-state luminescent properties of a series of H-bonded architectures based on dicationic tectons and dicyanometallate anions are described. Furthermore, a series of 2D assemblies offering channels occupied by solvent molecules will be presented and their solvation/ desolvation processes demonstrating their porous nature will be described.

\subsection{1}

\section{Luminescence}

Crystals containing $\left[\mathrm{M}^{\mathrm{I}}(\mathrm{CN})_{2}\right]^{-}$-type anion were shown to exhibit emission. For example, luminescent property of $\mathrm{KAg}^{\mathrm{I}}(\mathrm{CN})_{2} \cdot \mathrm{H}_{2} \mathrm{O}$ has been studied in the solid state [57]. More recently, examples of luminescent extended $\mathrm{H}$-bonded architectures have been described [58].

Interestingly, colorless crystals obtained by combining $2-2 \mathrm{H}^{+}$with $\left[\mathrm{M}^{\mathrm{I}}(\mathrm{CN})_{2}\right]^{-}$ $(\mathrm{M}=\mathrm{Ag}$ or $\mathrm{Au})$ were found to be strongly luminescent at room temperature (Figure 7.29). Their excitation at $370 \mathrm{~nm}$ generates a blue emission $\left(\lambda_{\max }=430\right.$ $\mathrm{nm})$ [55]. The luminescence is attributed to aurophilic or argentophilic interactions resulting from rather short $\mathrm{M}-\mathrm{M}$ distances. The latter parameter can be modulated within the backbone of the dicationic organic tecton through the variation of the length of the spacer connecting the two amidinium moieties.

\subsection{2}

\section{Porosity}

Porosity is one of the interesting features associated with molecular crystals. Although the majority of porous crystals derives from coordination networks or MOFs, few examples of crystals based on robust H-bonded networks have been reported [10, 34, 59].
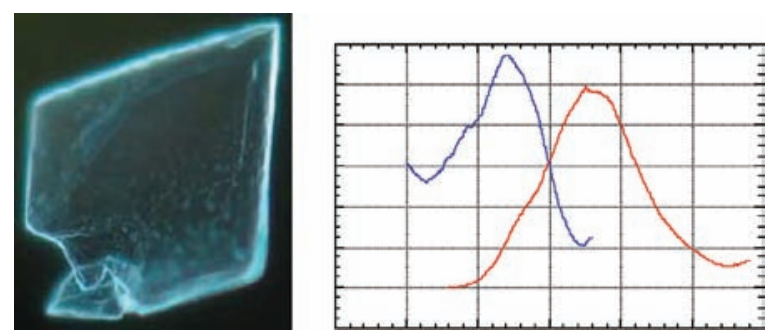

Figure 7.29 An image under fluorescent microscope of a luminescent crystal of $\left(2-2 \mathrm{H}^{+}\right)$ $\left(\left[\mathrm{Ag}^{\mathrm{\prime}}(\mathrm{CN})_{2}\right]_{2}\right.$ anion (left) and its excitation and emission spectra at $298 \mathrm{~K}$ (right) in the solid state. 
Some of the hybrid 2D networks presented above display channels and cavities filled with solvent molecules. In particular, the channels formed by H-bonded networks of the type $\left(\mathrm{X}-2 \mathrm{H}^{+}\right)_{3}\left(\left[\mathrm{M}^{\mathrm{III}}(\mathrm{CN})_{6}\right]^{3-}\right)_{2}(\mathrm{X}=\mathbf{2}$ or 3$)$ are filled with water molecules. The dehydration of these systems was induced thermally upon heating the crystal to $180^{\circ} \mathrm{C}$ and the resulting dehydrated samples were studied by XRD on single crystal. Several dehydration-rehydration cycles were performed and in all cases the initial number of water molecules $\left(7\right.$ for $2-2 \mathrm{H}^{+}$and 8 for $3-2 \mathrm{H}^{+}$) was observed by TGA analysis. In all cases, the dehydration-rehydration event takes place via single crystal-to-single crystal (SCSCT) transformation (Figure 7.30). This is a rare example of SCSCT based on H-bond networks [49b].

All crystals are thermally robust and their decomposition temperature is in the range of $240-300^{\circ} \mathrm{C}$ depending on the metal cation used. As expected through the
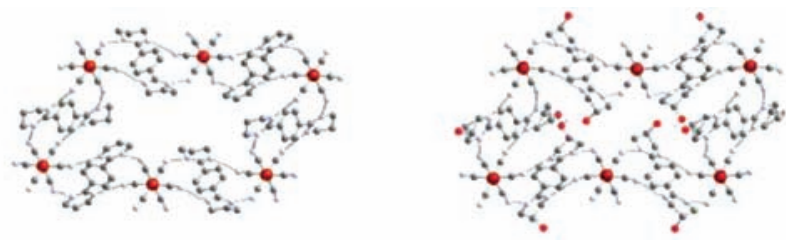

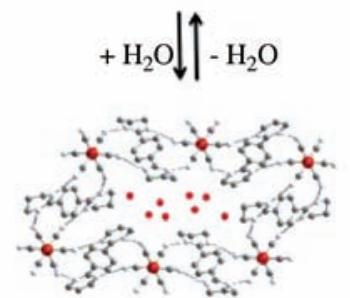

(a)

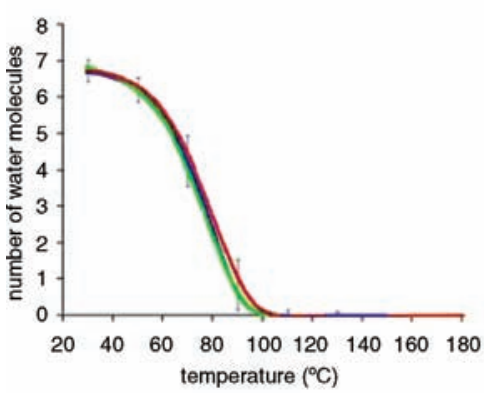

(c)

Figure 7.30 Portions of X-ray structure of the hydrated and dehydrated forms obtained through single crystal to single crystal transformation of isostructural crystals of $\left(\mathrm{X}-2 \mathrm{H}^{+}\right)_{3}\left(\left[\mathrm{M}^{\prime \prime \prime}(\mathrm{CN})_{6}\right]^{3-}\right)_{2}(\mathrm{M}=\mathrm{Fe}, \mathrm{Co}$, and $\mathrm{Cr})$ : (a) $X=2$ and (b) $X=3$. At the bottom, TGA

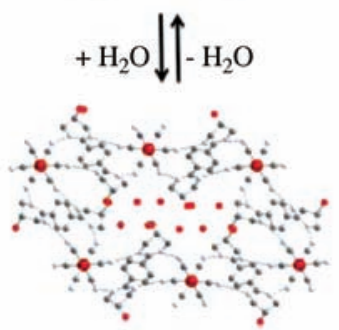

(b)

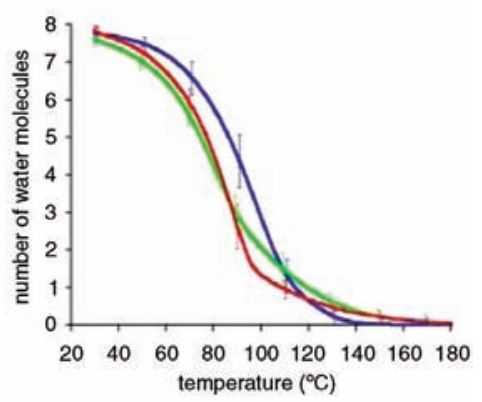

(d)

curves obtained for $\left(2-2 \mathrm{H}^{+}\right)_{3}\left(\left[\mathrm{M}^{\prime \prime \prime \prime}(\mathrm{CN})_{6}\right]^{3-}\right)_{2}$ (c) and $\left(3-2 \mathrm{H}^{+}\right)_{3}\left(\left[\mathrm{M}^{\prime \prime \prime}(\mathrm{CN})_{6}\right]^{3-}\right)_{2}(\mathrm{~d})(\mathrm{M}=\mathrm{Fe}$ in red, $\mathrm{Co}$ in blue, and $\mathrm{Cr}$ in green) showing the release of 7 and $8 \mathrm{H}_{2} \mathrm{O}$ molecules for $2-2 \mathrm{H}^{+}$ and $3-2 \mathrm{H}^{+}$, respectively. 
design of positively charged tectons $2-2 \mathrm{H}^{+}$and $3-2 \mathrm{H}^{+}$, the introduction of two $\mathrm{OH}$ groups as additional $\mathrm{H}$-bond donor/acceptor sites in $3-2 \mathrm{H}^{+}$interferes with the release of water molecules with a $\Delta T$ of about $40{ }^{\circ} \mathrm{C}$ between $2-2 \mathrm{H}^{+}$lacking the $\mathrm{OH}$ moieties and $3-2 \mathrm{H}^{+}$. This is related to the possibility of controlling the hydrophilic nature of the channels within the network through the decoration of the tecton's backbone with appropriate auxiliary groups (here hydroxyl groups) and thus the interactions between water molecules and the interior of the channels.

This has been demonstrated using a ternary system (solid solution, see Section 7.6.1.2) composed of the same anion $\left(\left[\mathrm{Cr}^{\mathrm{III}}(\mathrm{CN})_{6}\right]^{3-}\right)$ and two different cations $\left(2-2 \mathrm{H}^{+}\right)$and $\left(3-2 \mathrm{H}^{+}\right)$. The composition of the solid solution of formula $\left(2-2 \mathrm{H}^{+}\right)_{3 \gamma}\left(3-2 \mathrm{H}^{+}\right)_{3(1-\gamma)}\left(\left[\mathrm{Cr}^{\mathrm{III}}(\mathrm{CN})_{6}\right]^{3-}\right)_{2}$ was varied by changing $\gamma$ between 0 and 1 [60]. In Figure 7.31 are shown the thermal behavior when varying the ratio of the two cations. This study clearly demonstrates the possibility of finely tuning the temperature of water release through the nature of tectons.

The gas adsorption properties of the $\left(\mathrm{X}-2 \mathrm{H}^{+}\right)_{3}\left(\left[\mathrm{M}^{\mathrm{III}}(\mathrm{CN})_{6}\right]^{3-}\right)_{2}(\mathrm{M}=\mathrm{Fe}, \mathrm{Co}$, and $\mathrm{Cr}$ ) compounds were also studied, unfortunately, no adsorption of $\mathrm{N}_{2}$ or $\mathrm{H}_{2}$ was detected.

\subsection{3}

\section{Redox Properties in the Solid State}

Besides the exchange of guest molecules in porous frameworks, one may perform postsynthetic transformation (modification of the preformed crystalline material) using chemical or redox processes. This approach requires geometrically suitable and robust but flexible crystals. Very few examples of such transformations have been reported [61].

Using tecton 4, isostructural crystals of $\left(4-2 \mathrm{H}^{+}\right)_{3}\left(\left[\mathrm{Fe}^{\mathrm{III}}(\mathrm{CN})_{6}\right]^{3-}\right)_{2}$ and $\mathrm{X}_{2}(4-$ $\left.2 \mathrm{H}^{+}\right)_{3}\left(\left[\mathrm{Fe}^{\mathrm{II}}(\mathrm{CN})_{6}\right]^{4-}\right)_{2}(\mathrm{X}=\mathrm{K}, \mathrm{Na}, \mathrm{Rb}$, and $\mathrm{Cs})$ corresponding to two different oxidation states $\mathrm{Fe}(\mathrm{II})$ and $\mathrm{Fe}(\mathrm{III})$ have been formed (see Section 7.4.1.5).

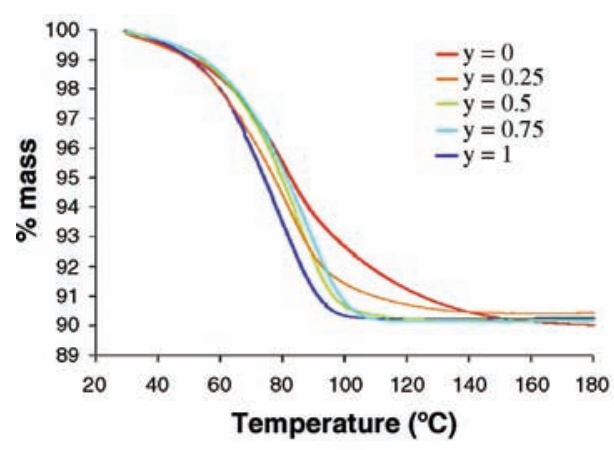

(a)

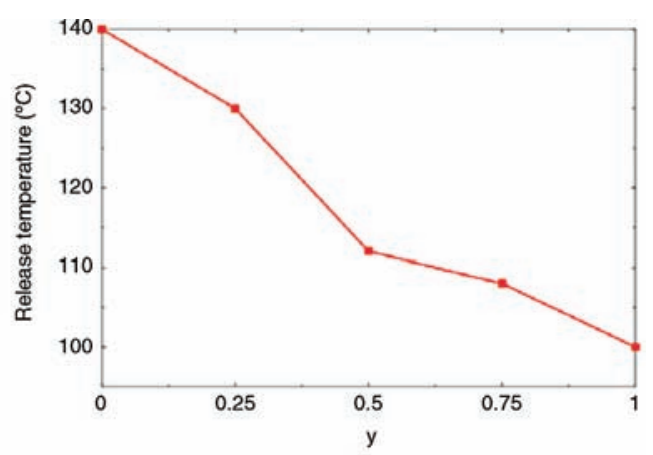

(b)

Figure 7.31 (a) TGA curves of molecular alloys $\left.\left(2-2 \mathrm{H}^{+}\right)_{3 \gamma}\left(3-2 \mathrm{H}^{+}\right)_{3(1-\gamma)}\left(\mathrm{Cr}^{\prime \prime \prime}(\mathrm{CN})_{6}\right]^{3-}\right)_{2}$ showing the fine-tuning of water release temperature. (b) Plot of the temperature of water release for $\left.\left(2-2 \mathrm{H}^{+}\right)_{3 \gamma}\left(3-2 \mathrm{H}^{+}\right)_{3(1-\gamma)}\left(\mathrm{Cr}^{\prime \prime \prime}(\mathrm{CN})_{6}\right]\right)_{2}$ versus $\gamma$. 

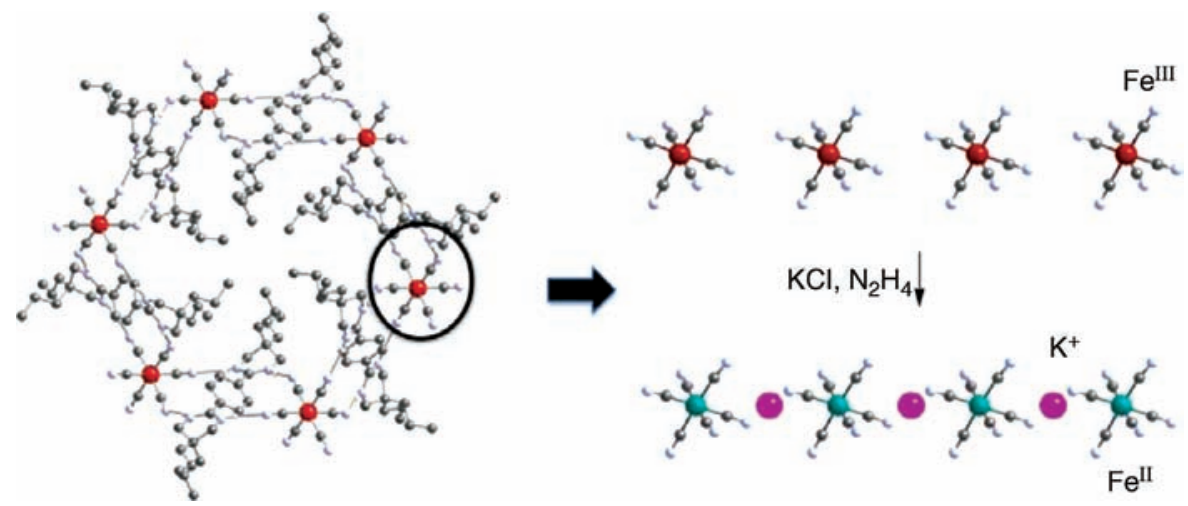

Figure 7.32 Portions of X-ray structure of $\left(4-2 \mathrm{H}^{+}\right)_{3}\left(\left[\mathrm{Fe}^{\mathrm{II \prime}}(\mathrm{CN})_{6}\right]^{3-}\right)_{2}$ when treated with $\mathrm{N}_{2} \mathrm{H}_{4}$ and $\mathrm{KCl}$, leading to $\mathrm{K}_{2}\left(4-2 \mathrm{H}^{+}\right)_{3}\left(\left[\mathrm{Fe}{ }^{\prime \prime}(\mathrm{CN})_{6}\right]^{4-}\right)_{2}$.

\subsubsection{Reduction in the Solid State}

Taking advantage of isostructurality and close metrics of the formed compounds, a postsynthetic transformation of crystals of $\left(4-2 \mathrm{H}^{+}\right)_{3}\left(\left[\mathrm{Fe}^{\mathrm{III}}(\mathrm{CN})_{6}\right]^{3-}\right)_{2}$ was demonstrated using the reduction of Fe(III) into Fe(II). Crystals of $\left(4-2 \mathrm{H}^{+}\right)_{3}\left(\left[\mathrm{Fe}^{\mathrm{III}}(\mathrm{CN})_{6}\right]^{3-}\right)_{2}$ were reduced by a mixture of hydrazine and $\mathrm{K}^{+}$cation without the loss of crystallinity. Indeed, the reduction process produced a polycrystalline powder of $\mathrm{K}_{2}\left(4-2 \mathrm{H}^{+}\right)_{3}\left(\left[\mathrm{Fe}^{\mathrm{II}}(\mathrm{CN})_{6}\right]^{4-}\right)_{2}[62]$. The reduction was monitored by XRPD as well as by IR. The reduction process corresponds to the injection of one electron per metallic center and the incorporation, between consecutive 2D formed H-bond networks, of one $\mathrm{K}^{+}$cation for each electron exchanged. The process reported here is a rare example of postcrystallization transformation taking place on molecular crystals composed of robust $\mathrm{H}$-bonded molecular networks (Figure 7.32).

\subsubsection{Formation of Mixed Valence Compounds}

A crystalline mixed valence phase starting from a mixture of $\mathrm{Cs}_{4} \mathrm{Fe}^{\mathrm{II}}(\mathrm{CN})_{6}$ and $\mathrm{Cs}_{3} \mathrm{Fe}^{\mathrm{III}}(\mathrm{CN})_{6}$ with $4-2 \mathrm{H}^{+}$was also obtained. The crystals obtained were analyzed by XRD that revealed the formation of a mixed valence $\mathrm{Fe}(\mathrm{II}) / \mathrm{Fe}(\mathrm{III})$ solid solution with 83/17 ratio $\left(\left(\mathrm{Cs}_{2}\left(4-2 \mathrm{H}^{+}\right)_{3}\left[\mathrm{Fe}^{\mathrm{II}}(\mathrm{CN})_{6}\right]_{2}{ }^{4-}\right)_{0.83}\left(\left(4-2 \mathrm{H}^{+}\right)_{3}-\left[\mathrm{Fe}^{\mathrm{III}}(\mathrm{CN})_{6}\right]_{2}{ }^{3-}\right)_{0.17}\right)$ (see Figure 7.33) [52]. Within the solid solution, the $\mathrm{Fe}(\mathrm{II})$ and $\mathrm{Fe}(\mathrm{III})$ cations are randomly distributed within the crystal. The presence of both oxidation states was further confirmed by IR spectroscopy.

\section{6}

\section{Design of Crystals Based on CAHB Networks}

In Section 7.4.1, a series of crystalline materials based on combinations of bisamidinium cations and polycyanometallate anions were described. A large number of obtained crystals were found to be isostructural. Taking advantage of the isostructur- 

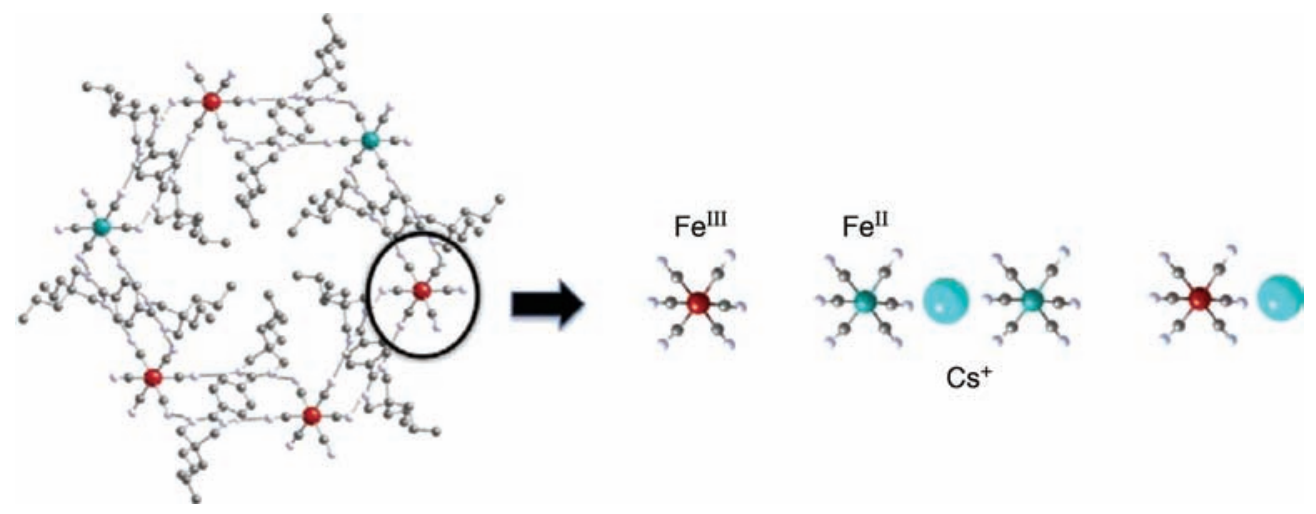

Figure 7.33 Portions of X-ray structure of $\left(\left(\mathrm{Cs}_{\mathbf{2}}\left(4-2 \mathrm{H}^{+}\right)_{3}\left[\mathrm{Fe}^{\prime \prime}(\mathrm{CNN})_{6}\right]^{4-}\right)_{0.83}\left(\left(4-2 \mathrm{H}^{+}\right)_{3}-\right.\right.$

$\left.\left.\left[\mathrm{Fe}^{\mathrm{III}}(\mathrm{CN})_{6}\right]_{2}{ }^{3-}\right)_{0.17}\right)$ with a random occupation of $\mathrm{Cs}^{+}$cation as well as distribution of $\mathrm{Fe}(\mathrm{II})$ and $\mathrm{Fe}$ (III) within the unit cell.

ality of some of the generated architectures, crystals with new shape and composition have been prepared. In particular, solid solutions as well as crystals of crystals, formed by epitaxial growth of crystals on seed crystals, have been obtained.

\subsection{1}

\section{Solid Solutions}

A crystalline solid solution is a mixture of at least two crystalline solids that coexist as a new crystalline solid. When the components of the solid solution are molecular entities, these systems are called molecular alloys [63]. The majority of reported molecular solid solutions are inorganic in nature. However, few examples of organic [64] or hybrid organic/inorganic materials have been reported [63a,b].

\subsubsection{Solid Solutions Using $\left(2-2 \mathrm{H}^{+}\right)_{2}\left(\left[\mathrm{M}^{\prime \prime}(\mathrm{CN})_{6}\right]\right)(\mathrm{M}=\mathrm{Fe}$ and $\mathrm{Ru})$}

The first reported solid solution was based on $\left(2-2 \mathrm{H}^{+}\right)_{2}\left(\left[\mathrm{M}^{\mathrm{II}}(\mathrm{CN})_{6}\right]^{4-}\right)(\mathrm{M}=\mathrm{Fe}$ or $\mathrm{Ru}$ ) [65]. As shown in Figure 7.34, the combination of $2-2 \mathrm{H}^{+}$with an equimolar mixture of $\left[\mathrm{Fe}^{\mathrm{II}}(\mathrm{CN})_{6}\right]^{4-}$ and $\left[\mathrm{Ru}^{\mathrm{II}}(\mathrm{CN})_{6}\right]^{4-}$ leads to an homogenous phase of formula $\left(\left(2-2 \mathrm{H}^{+}\right)_{2}\left[\mathrm{Ru}(\mathrm{CN})_{6}\right]^{4-}{ }_{0.5}\left[\mathrm{Fe}(\mathrm{CN})_{6}\right]^{4-}{ }_{0.5}\right)$. The latter crystalline phase displays an intermediate color between the pure $\left(\left(2-2 \mathrm{H}^{+}\right)_{2}\left[\mathrm{Ru}(\mathrm{CN})_{6}\right]^{4-}\right)$ and the pure $((2-$ $\left.\left.2 \mathrm{H}^{+}\right)_{2}\left[\mathrm{Fe}(\mathrm{CN})_{6}\right]^{4-}\right)$. As expected, crystallographic parameters following the Vegard's law [66] are also intermediate.

\subsubsection{Solid Solutions Using $\left(X-2 \mathrm{H}^{+}\right)_{3}\left(\left[\mathrm{M}^{\prime \prime \prime}(\mathrm{CN})_{6}\right]\right)_{2}(\mathrm{X}=\mathbf{2}$ or $3, \mathrm{M}=\mathrm{Fe}, \mathrm{Cr}$, or Co)} The example described above was based on a ternary system (one dication and two anions). More sophisticated and tunable systems have been generated using 2D porous systems using two different organic tectons and three different anions (formula $\left(\mathrm{X}-2 \mathrm{H}^{+}\right)_{3}\left(\left[\mathrm{M}^{\mathrm{III}}(\mathrm{CN})_{6}\right]^{3-}\right)_{2} \quad(\mathrm{X}=\mathbf{2}$ or $3, \mathrm{M}=\mathrm{Fe}, \mathrm{Cr}$, or Co). Based on crystallographic parameters given in Table 7.1, systems based on up to five components have been generated [60]. As an example shown in Figure 7.35, while keeping 


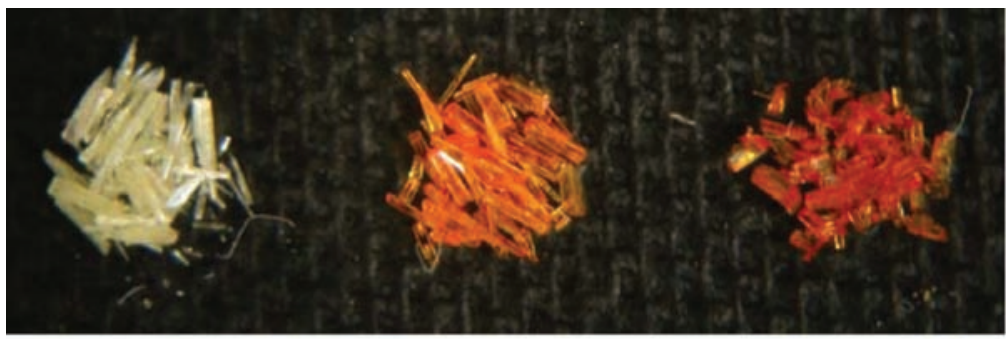

(a)

(b)

(c)

Figure 7.34 Pictures of crystals of $\left.\left(2-2 \mathrm{H}^{+}\right)_{2}\left(\mathrm{Ru}^{\prime \prime}(\mathrm{CN})_{6}\right]^{4-}\right)(\mathrm{a})$, the solid solution $\left(\left(2-2 \mathrm{H}^{+}\right)_{2}[\mathrm{Ru}\right.$ $\left.\left.(\mathrm{CN})_{6}\right]^{4-}{ }_{0.5}\left[\mathrm{Fe}(\mathrm{CN})_{6}\right]^{4-}{ }_{0.5}\right)(\mathrm{b})$, and $\left.\left(2-2 \mathrm{H}^{+}\right)_{2}\left(\mathrm{Fe}^{\prime \prime}(\mathrm{CN})_{6}\right]^{4-}\right)(\mathrm{c})$.

the same cationic tecton, an intermediate case has been obtained by varying the anionic part of the system. Thus, a solid solution of the following formula $\left(3-2 \mathrm{H}^{+}\right)_{3}\left(\left[\mathrm{Fe}(\mathrm{CN})_{6}\right]^{3-}{ }_{2 / 3}\left[\mathrm{Co}(\mathrm{CN})_{6}\right]^{3-}{ }_{2 / 3}\left[\mathrm{Cr}(\mathrm{CN})_{6}\right]^{3-}{ }_{2 / 3}\right)$ was prepared.

\subsection{2}

\section{Epitaxial Growth of Isostructural Crystals}

\subsubsection{Principles and Examples}

Novel approaches for the fabrication of patterned and bulk crystals [67] have been developed recently. These investigations are motivated by the use of these crystalline materials in optical applications such as electro-optics or as photorefractive materials [68]. Only a limited number of monocrystalline multilayers based on combination of coordination and hydrogen bonding have been reported so far [33, 34]. Recently, few examples based on pure coordination networks have been published showing the increasing interest in this type of approach [69].

As stated above, using the isostructurality between a series of crystals based on the combination of amidinium-based tectons and cyanometallates (see Section 7.4.1), crystals of crystals also called crystalline molecular alloys have been generated by $3 \mathrm{D}$ epitaxial growth.

The first example of crystals of crystals reported was based on (2$\left.2 \mathrm{H}^{+}\right)_{3}\left(\left[\mathrm{M}^{\mathrm{III}}(\mathrm{CN})_{6}\right]^{3-}{ }_{2}\right)(\mathrm{M}=\mathrm{Fe}$ and $\mathrm{Co})$ system [63b]. However, due to the fragility of the crystals, the more robust system based on $\left(2-2 \mathrm{H}^{+}\right)_{2}\left(\left[\mathrm{M}^{\mathrm{II}}(\mathrm{CN})_{6}\right]^{4-}\right)(\mathrm{M}=\mathrm{Fe}$ and $\mathrm{Ru}$ ) was further investigated. A greater difference in color between $\left[\mathrm{Fe}^{\mathrm{II}}(\mathrm{CN})_{6}\right]^{4-}$ ) (orange) and $\left[\mathrm{Ru}^{\mathrm{II}}(\mathrm{CN})_{6}\right]^{4-}$ ) (colorless) complexes constitutes another advantage allowing a better visualization of the growth process. Using this system, a monocrystalline layer of $\left.\left(2-2 \mathrm{H}^{+}\right)_{2}\left(\left[\mathrm{Fe}^{\mathrm{II}}(\mathrm{CN})_{6}\right]^{4-}\right)\right]$ (orange) on a single crystal of (2$\left.2 \mathrm{H}^{+}\right)_{2}\left(\left[\mathrm{Ru}^{\mathrm{II}}(\mathrm{CN})_{6}\right]^{4-}\right.$ ) (colorless) was grown through epitaxial monocrystal growth (see Figure 7.36) [65]. The growth of successive generations was pursued up to generation III (Figure 7.36). The growth process could be performed independent of the starting seed crystal.

Other interesting examples are related to solid solutions (see Section 7.6.1). We have recently shown the possibility to growing crystals of crystals using a single crystal based 


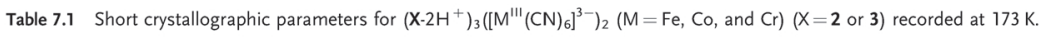

\begin{tabular}{|c|c|c|c|c|c|c|}
\hline \multirow[t]{2}{*}{ Formula } & \multicolumn{2}{|c|}{$\left(\mathrm{X}-2 \mathrm{H}^{+}\right)_{3}\left(\left[\mathrm{Cr}(\mathrm{CN})_{6}\right]_{2}^{3-}\right)$} & \multicolumn{2}{|c|}{$\left(\mathrm{X}-2 \mathrm{H}^{+}\right)_{3}\left(\left[\mathrm{Fe}(\mathrm{CN})_{6}\right]_{2}^{3-}\right)$} & \multicolumn{2}{|c|}{$\left(\mathrm{X}-2 \mathrm{H}^{+}\right)_{3}\left(\left[\mathrm{Co}(\mathrm{CN})_{6}\right]_{2}^{3-}\right)$} \\
\hline & $\mathbf{X}=\mathbf{2}$ & $X=3$ & $X=2$ & $x=3$ & $X=\mathbf{2}$ & $X=3$ \\
\hline Mwt & 1275.37 & 1389.39 & 1283.07 & 1397.09 & 1289.23 & 1403.25 \\
\hline Crystal system & Monoclinic & Monoclinic & Triclinic & Monoclinic & Triclinic & Monoclinic \\
\hline Space group & $\mathrm{P} 2(1) / n$ & $\mathrm{P} 2(1) / n$ & P-1 & $\mathrm{P} 2(1) / n$ & P-1 & $\mathrm{P} 2(1) / n$ \\
\hline$a(\AA)$ & $7.1142(4)$ & $7.1190(2)$ & $7.0949(3)$ & $7.0978(5)$ & $7.0982(4)$ & $7.1180(10)$ \\
\hline$b(\hat{A})$ & $21.4319(13)$ & $22.3250(6)$ & $12.3765(5)$ & $22.2254(16)$ & $12.3509(7)$ & $22.252(4)$ \\
\hline$c(\AA)$ & $20.9403(13)$ & $21.0110(6)$ & $17.9534(7)$ & $20.6357(12)$ & $17.8586(10)$ & $20.508(4)$ \\
\hline$\alpha$ (deg) & 90 & 90 & $83.580(2)$ & 90 & $83.535(2)$ & 90 \\
\hline$\beta$ (deg) & $91.702(2)$ & $92.8190(17)$ & $87.6101(10)$ & $92.363(3)$ & $87.4280(10)$ & $92.239(6)$ \\
\hline$\gamma(\mathrm{deg})$ & 90 & 90 & $83.9340(10)$ & 90 & $83.967(2)$ & 90 \\
\hline$V\left(\AA^{3}\right)$ & $3191.4(3)$ & $3335.27(16)$ & $1557.12(11)$ & $3252.5(4)$ & $1546.21(15)$ & $3245.8(10)$ \\
\hline
\end{tabular}




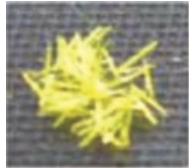

(a)

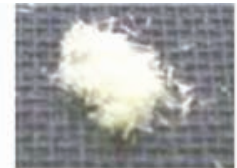

(b)

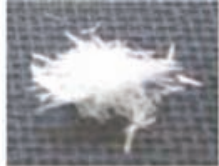

(c)

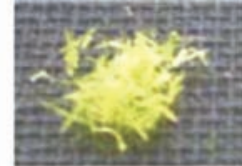

(d)

Figure 7.35 Pictures of pure crystals of $\left(3-2 \mathrm{H}^{+}\right)_{3}\left(\left[\mathrm{Fe}(\mathrm{CN})_{6}\right]^{3-}{ }_{2}\right)(\mathrm{a}),\left(3-2 \mathrm{H}^{+}\right)_{3}\left(\left[\mathrm{Cr}(\mathrm{CN})_{6}\right]^{3-}{ }_{2}\right)(\mathrm{b})$, $\left(3-2 \mathrm{H}^{+}\right)_{3}\left(\left[\mathrm{Co}(\mathrm{CN})_{6}\right]^{3-}{ }_{2}\right)(\mathrm{c})$, and the ternary crystalline alloy $\left(3-2 \mathrm{H}^{+}\right)_{3}\left(\left[\mathrm{Fe}(\mathrm{CN})_{6}\right]_{2 / 3}^{3-}[\mathrm{Co}\right.$ $\left.\left.(\mathrm{CN})_{6}\right]^{3-}{ }_{2 / 3}\left[\mathrm{Cr}(\mathrm{CN})_{6}\right]^{3-}{ }_{2 / 3}\right)(\mathrm{d})$.

on a solid solution [60]. With systems based on $\left(3-2 \mathrm{H}^{+}\right)_{3}\left(\left[\mathrm{M}^{\mathrm{III}}(\mathrm{CN})_{6}\right]^{3-}\right)_{2}(\mathrm{M}=\mathrm{Fe}$, $\mathrm{Cr}$, or Co) combinations, the growth of a solid solution crystal of $\left(2-2 \mathrm{H}^{+}\right)_{3}\left(\left[\mathrm{Cr}^{\mathrm{III}}(\mathrm{CN})_{6}\right]^{3-}\right)_{2}$ on $\left(3-2 \mathrm{H}^{+}\right)_{3}\left(\left[\mathrm{Cr}^{\mathrm{III}}(\mathrm{CN})_{6}\right]^{3-}\left[\mathrm{Fe}^{\mathrm{III}}(\mathrm{CN})_{6}\right]^{3-}\right)$ oron $\left(3-2 \mathrm{H}^{+}\right)_{3}\left(\left[\mathrm{Co}^{\mathrm{III}}(\mathrm{CN})_{6}\right]^{3-}\left[\mathrm{Fe}^{\mathrm{III}}(\mathrm{CN})_{6}\right]^{3-}\right)$ was performed, as shown in Figure 7.37.

\subsubsection{Study of the Interface}

The growth mechanism of composite crystals was studied by investigating the nature of the interface on robust $\left(2-2 \mathrm{H}^{+}\right)_{2}\left(\left[\mathrm{M}^{\mathrm{II}}(\mathrm{CN})_{6}\right]^{4-}\right)(\mathrm{M}=\mathrm{Fe}$ and $\mathrm{Ru})$ systems. In order to determine the nature of the metal distribution perpendicular to the interface, the

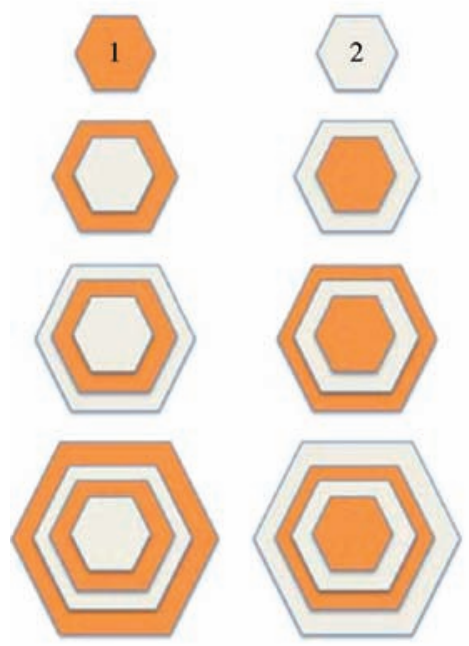

(a)

Figure 7.36 (a) Schematic representation of slices of composite crystals and their consecutives generations. The procedure starts with the pure crystals of $\left(2-2 \mathrm{H}^{+}\right)_{2}\left(\left[\mathrm{Ru}^{\prime \prime}(\mathrm{CN})_{6}\right]^{4-}\right)$ or $\left(2-2 \mathrm{H}^{+}\right)_{2}\left(\left[\mathrm{Fe}^{\mathrm{II}}(\mathrm{CN})_{6}\right]^{4-}\right)$ and the following

\section{0 $12 \mathbf{~ m m}$}

Lnلس

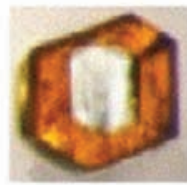

a

C

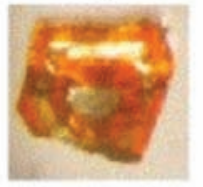

e

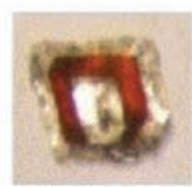

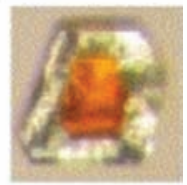

b

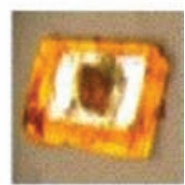

d

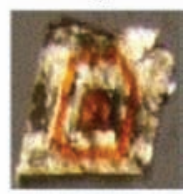

f (b)

generations are obtained, in an iterative fashion, by immersing the crystals of precedent generation into a solution containing tecton $2-2 \mathrm{H}^{+}$and the other cyanometallate anion. (b) Pictures of slices of the different composite crystals. 


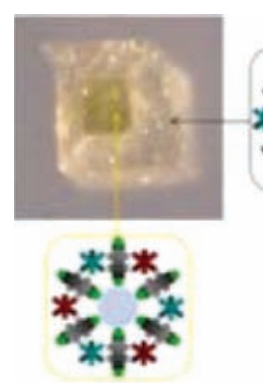

(a)

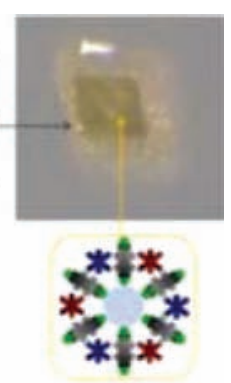

(b)

Figure 7.37 Slices of composite crystals obtained by epitaxial growth of $\left(2-2 \mathrm{H}^{+}\right)_{3}\left(\left[\mathrm{Cr}\left(\mathrm{III}(\mathrm{CN})_{6}\right]^{3-}\right)_{2}\right.$ on $\left(3-2 \mathrm{H}^{+}\right)_{3}\left(\left[\mathrm{Cr}^{\prime \prime \prime}(\mathrm{CN})_{6}\right]^{3-}\left[\mathrm{Fe}^{\prime \prime \prime}(\mathrm{CN})_{6}\right]^{3-}\right)(\mathrm{a})$ or on $\left(3-2 \mathrm{H}^{+}\right)_{3}\left(\left[\mathrm{Co}^{\prime \prime \prime}(\mathrm{CN})_{6}\right]^{3-}\left[\mathrm{Fe}^{\prime \prime \prime \prime}(\mathrm{CN})_{6}\right]^{3-}\right)(\mathrm{b})$. Reproduced with permission from Ref. [60]. Copyright 2009 Royal Chemical Society.

latter was studied by both TEM and FIB/STEM microscopies using energy dispersive spectroscopy (EDS) (see Figure 7.38). The study revealed a diffuse interface between the two isostructural phases extending over about $0.7 \mathrm{~mm}$ [70], implying probably a partial redissolution of the surface during the growth process of the pure phase on the preformed crystal.

In order to elucidate this mechanism, using AFM, some additional characterizations were performed on the same system.

\subsubsection{In Situ Study of the Growth}

Real-time in situ atomic force microscopy (AFM) was performed on different crystals of $\left(2-2 \mathrm{H}^{+}\right)_{2}\left(\left[\mathrm{Fe}^{\mathrm{II}}(\mathrm{CN})_{6}\right]^{4-}\right)$ and $\left(2-2 \mathrm{H}^{+}\right)_{2}\left(\left[\mathrm{Ru}^{\mathrm{II}}(\mathrm{CN})_{6}\right]^{4-}\right)$, and the perfectly epitaxial growth could also be demonstrated at the atomic level (see Figure 7.39). The crystal topography and roughness under various conditions revealed that the interface observed during epitaxial crystals growth depends on the nature of the surface (roughness) and on the way the crystal are dried before immersion in the media [71]. The roughness of the growth interface can be regulated using specific growth

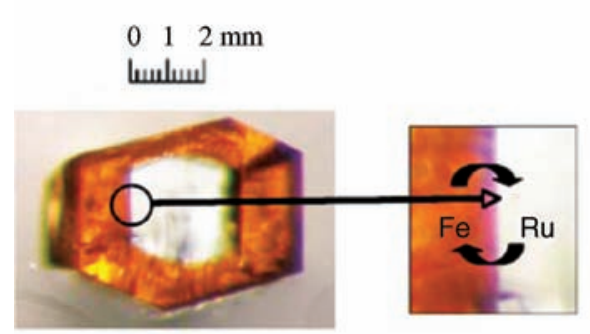

(a)

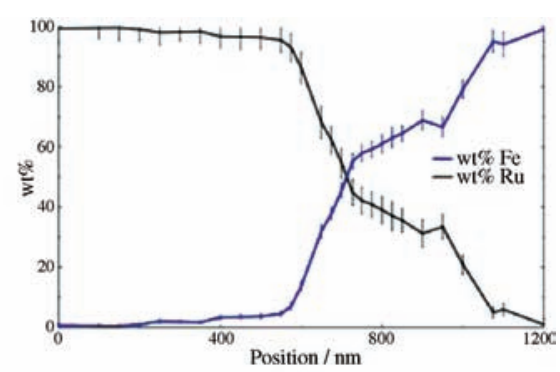

(b)
Figure 7.38 (a) Heterocrystal formed through epitaxial growth of a shroud of $\left(2-2 \mathrm{H}^{+}\right)_{2}\left(\left[\mathrm{Fe}^{\prime \prime}(\mathrm{CN})_{6}\right]^{4-}\right)$ (orange) on a core seed crystal of $\left(2-2 \mathrm{H}^{+}\right)_{2}\left(\left[\mathrm{Ru}^{\prime \prime}(\mathrm{CN})_{6}\right]^{4-}\right)$ (colorless). (b) EDS profiles of the $\mathrm{Fe}$ and $\mathrm{Ru}$ content across the heterocrystal interface, expressed as count rate for $\mathrm{Fe}-\mathrm{K}$ and $\mathrm{Ru}-\mathrm{L}$ signals and weight percent. 
$224 \mid 7$ Molecular Tectonics: Design of Hybrid Networks

(a)

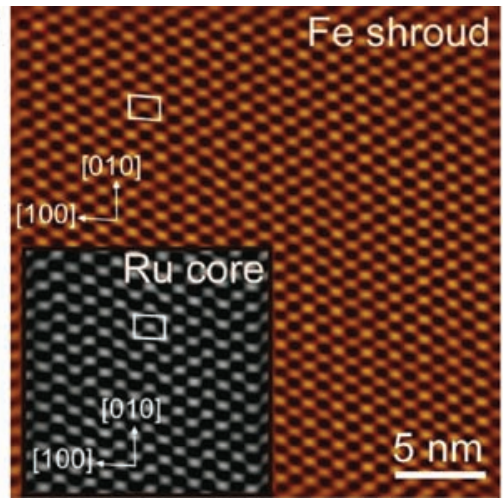

Figure 7.39 (a) $\left(2-2 \mathrm{H}^{+}\right)_{2}\left(\left[\mathrm{Fe}^{\prime \prime}(\mathrm{CN})_{6}\right]^{4-}\right)$ over layer grown on the (001) face of a $(2$ $\left.2 \mathrm{H}^{+}\right)_{2}\left(\left[\mathrm{Ru}^{\prime \prime}(\mathrm{CN})_{6}\right]^{4-}\right)$ crystal. (b) (2$\left.2 \mathrm{H}^{+}\right)_{2}\left(\left[\mathrm{Ru}^{\prime \prime}(\mathrm{CN})_{6}\right]^{4-}\right)$ over layer grown on the (001) face of a $\left(2-2 \mathrm{H}^{+}\right)_{2}\left(\left[\mathrm{Fe}^{\prime \prime}(\mathrm{CN})_{6}\right]^{4-}\right)$ crystal. (b)

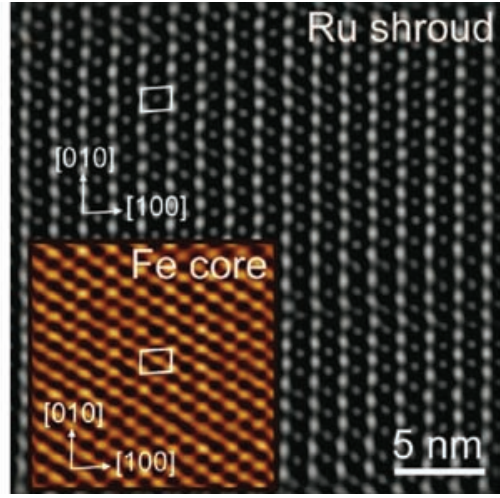

Both cases display an extraordinary degree of epitaxial alignment between the core and the shroud, the sides of the rectangular crystals. Reproduced with permission from Ref. [71]. Copyright 2009 American Chemical Society.

protocols (seeding time, drying method) that minimize the intermixing of the two compounds.

\section{7}

\section{Conclusion}

Using concepts developed in the field of molecular recognition of anions in solution, cationic molecular tectons capable of forming CAHB molecular networks in the crystalline phase by iteration of the recognition pattern were designed. Among the many examples of $\mathrm{H}$-bonded networks reported in the literature, the use of bisamidinium derivatives as dicationic tectons and polycyanometallates of different charge and geometry as anionic tectons appeared as the most effective system. Indeed, the design of robust and reliable mode of recognition between the amidinium acidic hydrogen atoms as donors and cyanide groups bound to metal centers as acceptors not only allowed to generate a large variety of networks with different dimensionality but also afforded functional crystals displaying either optical properties or porosity. Using the isostructurality between several crystals, new materials such as solid solutions combining up to five different components have been fabricated. Furthermore, crystalline materials composed of metal cyanide complexes with two different oxidation states, mainly Fe(II) and Fe(III) (mixed valence systems), have been obtained. Using a reductive process, the possibility of postcrystallization modifications was demonstrated by transforming Fe(III)-based crystals into Fe(II)based crystalline materials. Finally, new classes of H-bonded crystals based on 3D epitaxial growth of crystalline layers on seed crystals (crystals of crystals) afforded hierarchical molecular alloys with tunable parameters. A step toward bridging the gap between structural aspects of crystal engineering and the design and control of 
physical properties (functional crystalline materials) was taken that should lead to new solid state materials displaying predicted and tailored properties.

\section{Acknowledgments}

Many thanks to Dr. P. Dechambenoit, Dr. C. Paraschiv, Dr. G. Marinescu, Dr. O. Félix, Dr. A. De Cian, Professor J.-M. Planeix, and N. Kyritsakas who performed part of the work. Professor M.D. Ward (NYU) is also kindly acknowledged for AFM measurements and Professor E. Brès (Université de Lille) for electronic microscopy. We also acknowledge financial support from the Université de Strasbourg, Institut Universitaire de France, The Frontier Research in Chemistry (FRC), Strasbourg, the CNRS, the Ministry of Research and Education, and Marie Curie Est Actions FUMASSEC Network (Contract No. MEST-CT-2005-020992).

\section{References}

1 (a) Whitesides, G.M., Mathias, J.P., and Seto, T. (1991) Molecular self-assembly and nanochemistry: a chemical strategy for the synthesis of nanostructures. Science, 254, 1312-1319; (b) Lindsey, J.S. (1991) Self-assembly in synthetic routes to molecular devices. Biological principles and chemical perspectives: a review. New J. Chem., 15, 153-180.

2 Lehn, J.-M. (1995) Supramolecular Chemistry, Concepts and Perspectives, Wiley-VCH Verlag GmbH, Weinheim.

3 (a) Schmidt, G.M. (1971)

Photodimerization in the solid state. Pure Appl. Chem., 27, 647-678; (b) Dunitz, J.D. (1991) Phase transitions in molecular crystals from a chemical viewpoint. Pure Appl. Chem., 63, 177-185; (c) Dunitz, J.D. (1996) Perspectives in Supramolecular Chemistry, vol. 2 (ed. G.R. Desiraju), John Wiley \& Sons, Inc., New York.

4 (a) Aakeröy, C.B. (1997) Crystal engineering: strategies and architectures. Acta Crystallogr., B53, 569-586; (b) Braga, D. and Grepioni, F. (2000) Intermolecular interactions in nonorganic crystal engineering. Acc. Chem. Res., 33, 601-608; (c) Moulton, B. and Zaworotko, M.J. (2001) From molecules to crystal engineering: supramolecular isomerism and polymorphism in network solids. Chem. Rev., 101, 1629-1658; (d) Braga, D., Desiraju, G.R., Miller, J.S., Orpen, A.G., and Price, S.L. (2002) Innovation in crystal engineering. CrystEngComm, 4, 500-509; (e) Sommerdijk, N.A.J.M. (2003) Crystal design and crystal engineering. Angew. Chem., Int. Ed., 42, 3572-3574; (f) Braga, D., Brammer, L., and Champness, N.R. (2005) New trends in crystal engineering. CrystEngComm, 7, 1-19; (g) Brammer, L. (2004) Developments in inorganic crystal engineering. Chem. Soc. Rev., 33, 476-489.

5 (a) Simard, M., Su, D., and Wuest, J.D. (1991) Use of hydrogen bonds to control molecular aggregation. Selfassembly of three-dimensional networks with large chambers. J. Am. Chem. Soc., 113, 4696-4698; (b) Mann, S. (1993) Molecular tectonics in biomineralization and biomimetic materials chemistry. Nature, 365, 499-505.

6 Hosseini, M.W. (2004) Reflexion on molecular tectonics. CrystEngComm, 6, 318-322.

7 Desiraju, G.D. (1989) Crystal Engineering: The Design of Organic Solids, Elsevier, New York.

8 Hosseini, M.W. (2005) Molecular tectonics: from simple tectons to complex molecular networks. Acc. Chem. Res., 38, 313-323. 
226 7 Molecular Tectonics: Design of Hybrid Networks

9 Hosseini, M.W. (2005) Self-assembly and generation of complexity. Chem.

Commun., 5825-5829.

10 Brunet, P., Simard, M., and Wuest, J.D. (1997) Molecular tectonics. Porous hydrogen-bonded networks with unprecedented structural integrity. J. Am. Chem. Soc., 119, 2737-2738.

11 Dunitz, J.D. (2003) Are crystal structures predictable? Chem. Commun., 545-548.

12 (a) Price, S.L. (2004) Quantifying intermolecular interactions and their use in computational crystal structure prediction. CrystEngComm, 6, 344-354;

(b) Dunitz, J.D. and Gavezzoti, A. (2005) Molecular recognition in organic crystals: directed intermolecular bonds or nonlocalized bonding. Angew. Chem., Int Ed., 44, 1766-1787.

13 Gavezzotti, A. (1994) Are crystal structures predictable? Acc. Chem. Res., 27, 309-314.

14 (a) Ermer, O. (1988) Five-fold diamond structure of adamantane-1,3,5,7tetracarboxylic acid. J. Am. Chem. Soc., 110, 3747-3754; (b) Aakeröy, C.B. and Seddon, K.R. (1993) The hydrogen bond and crystal engineering. Chem. Soc. Rev., 22, 397-407; (c) Subramanian, S. and Zaworotko, M.J. (1994) Exploitation of the hydrogen bond: recent developments in the context of crystal engineering. Coord. Chem. Rev., 137, 357-401; (d) Lawrence, D.S., Jiang, T., and Levett, M. (1995) Self-assembling supramolecular complexes. Chem. Rev., 95, 2229-2260; (e) Stoddart, J.F. and Philip, D. (1996) Selfassembly in natural and unnatural systems. Angew. Chem., Int. Ed. Engl., 35, 1154-1196; (f) Fredericks, J.R. and Hamilton, A.D. (1996) in Comprehensive Supramolecular Chemistry, vol. 9 (series eds J.L. Atwood, J.E. Davis, D.D. Macnico, and F. Vögtle, eds J.P. Sauvage and M.W. Hosseini), Elsevier, Oxford, pp. 565-594.

15 (a) Batten, S.R. and Robson, R. (1998) Interpenetrating nets: ordered periodic entanglement. Angew. Chem., Int. Ed., 37, 1460-1494; (b) Blake, A.J., Champness, N.R., Hubberstey, P., Li, W.-S., Withersby, M.A., and Schröder, M. (1999) Inorganic crystal engineering using self-assembly of tailored building-blocks. Coord. Chem.
Rev., 193, 117-138; (c) Hosseini, M.W. (1999) NATO ASI Series, Series C, vol. 538 (eds D. Braga, F. Grepiono, and G. Orpen), Kluwer, Dordrecht, The Netherlands, pp. 181-208;(d) Eddaoui, M., Moler, D.B., Li, H., Chen, B., Reineke, T.M., O'Keeffe, M., and Yaghi, O.M. (2001) Modular chemistry. secondary building units as a basis for the design of highly porous and robust metal-organic carboxylate frameworks. Acc. Chem. Res., 34, 319-330; (e) Swiergers, G.F. and Malefetse, T.J. (2000) New self-assembled structural motifs in coordination chemistry. Chem. Rev., 100, 3483-3538; (f) Janiak, C. (2003) Engineering coordination polymers towards applications. Dalton Trans., 2781-2804; (g) Ferey, G. (2008) Hybrid porous solids: past, present, future. Chem. Soc. Rev., 37, 191-214.

16 Hill, D.J., Moi, M.J., Prince, R.B., Hughes, T.S., and Moore, J.S. (2001) A field guide to foldamers. Chem. Rev., 101, 3893-4011.

17 Hosseini, M.W. and De Cian, A. (1998) Crystal engineering: molecular networks based on inclusion phenomena. Chem. Commun., 727-734.

18 (a) Jeffrey, G.A. (1997) An Introduction to Hydrogen Bonding, Oxford University Press, Oxford;(b) Taylor, R. and Kennard, O. (1984) Hydrogen-bond geometry in organic crystals. Acc. Chem. Res., 17, 320-326; (c) Etter, M.C. (1990) Encoding and decoding hydrogen-bond patterns of organic compounds. Acc. Chem. Res., 23, 120-126.

19 Steiner, T. (2002) The hydrogen bond in the solid state. Angew. Chem., Int. Ed., 41, 48-76.

20 Ward, M.D. (2005) Design of crystalline molecular networks with charge-assisted hydrogen bonds. Chem. Commun., 5838-5842.

21 (a) Sliwa, M., Letard, S., Malfant, I., Nierlich, M., Lacroix, P.G., Asahi, T., Masuhara, H., Yu, P., and Nakatani, K. (2005) Design, synthesis, structural and nonlinear optical properties of photochromic crystals: toward reversible molecular switches. Chem. Mater., 17, 4727-4735; (b) Datta, A. and Pati, S.K. (2006) Dipolar interactions and hydrogen bonding in supramolecular aggregates: 
understanding cooperative phenomena for 1st hyperpolarizability. Chem. Soc. Rev., 35, 1305-1323; (c) Cariati, E., Macchi, R., Robert, D., Ugo, R., Galli, S., Casati, N., Macchi, P., Sironi, A., Bogani, L.,

Caneschi, A., and Gatteschi, D. (2007) Polyfunctional inorganic-organic hybrid materials: an unusual kind of NLO active layered mixed metal oxalates with tunable magnetic properties and very large second harmonic generation. J. Am. Chem. Soc., 129, 9410-9420.

22 (a) Miller, J.S. (2000) Organometallic- and organic-based magnets: new chemistry and new materials for the new millennium. Inorg. Chem., 39, 4392-4408; (b) Andruh, M. (2007) Oligonuclear complexes as tectons in crystal engineering: structural diversity and magnetic properties. Chem. Commun., 2565-2567; (c) Maspoch, D., Ruiz-Molina, D., and Veciana, J. (2007) Old materials with new tricks: multifunctional openframework materials. Chem. Soc. Rev., 36, 770-818.

23 (a) Ockwig, N.W., Delgado-Friedrichs, O., O'Keefe, M., and Yaghi, O.M. (2005) Reticular chemistry: occurrence and taxonomy of nets and grammar for the design of frameworks. Acc. Chem. Res., 38, 176-182; (b) Rosseinsky, M.J. (2004) Recent developments in metal-organic framework chemistry: design, discovery, permanent porosity and flexibility. Microporous. Mesoporous. Mater., 73, 15-30; (c) Kitagawa, S., Kitaura, R., and Noro, S. (2004) Functional porous coordination polymers. Angew. Chem., Int. Ed., 43, 2334-2375; (d) Férey, G. (2005) Crystallized frameworks with giant pores: Are there limits to the possible? Acc. Chem. Res., 38, 217-225.

24 (a) Russell, A., Etter, M.C., and Ward, M.D. (1994) Layered materials by molecular design: structural enforcement by hydrogen bonding in guanidinium alkane- and arenesulfonates. J. Am. Chem. Soc., 116, 1941-1952; (b) Russell, V.A., Evans, C.C., Li, W., and Ward, M.D. (1997) Nanoporous molecular sandwiches: pillared two-dimensional hydrogenbonded networks with adjustable porosity. Science, 276, 575-579; (c) Holman, K.T.,
Pivovar, A.M., Swift, J.A., and Ward, M.D. (2001) Metric engineering of soft molecular host frameworks. Acc. Chem. Res., 34, 107-118; (d) Holman, K.T., Pivovar, A.M., and Ward, M.D. (2001) Engineering crystal symmetry and polar order in molecular host frameworks. Science, 294 1907-1911; (e) Custelcean, R. and Ward, M.D. (2005) Chiral discrimination in low-density hydrogenbonded frameworks. Cryst. Growth Des., 5, 2277-2287; (f) Liu, Y. and Ward, M.D. (2009) Molecular capsules in modular frameworks. Cryst. Growth Des., 9, 3859-3861.

25 (a) Martin, S.M., Yonezawa, J., Horner, M.J., Macosko, C.W., and Ward, M.D. (2004) Structure and rheology of hydrogen bond reinforced liquid crystals. Chem. Mater., 16, 3045-3055; (b) Horner, M.J., Holman, K.T., and Ward, M.D. (2007) Architectural diversity and elastic networks in hydrogen-bonded host frameworks: from molecular jaws to cylinders. J. Am. Chem. Soc., 129, 14640-14660; (c) Comotti, A., Bracco, S., Sozzani, P., Hawxwell, S.M., Hu, C., and Ward, M.D. (2009) Guest molecules confined in amphipathic crystals as revealed by X-ray diffraction and MAS NMR. Cryst. Growth Des., 9, 2999-3002; (d) Soegiarto, A.C. and Ward, M.D. (2009) Cooperative polar ordering of acentric guest molecules in topologically controlled host frameworks. Cryst. Growth Des., 9, 3803-3815.

26 (a) Lewis, G.R. and Orpen, A.G. (1998) A metal-containing synthon for crystal engineering: synthesis of the hydrogen bond ribbon polymer $\left[4,4-\mathrm{H}_{2}\right.$ bipy $]\left[\mathrm{MCl}_{4}\right]$ (M=Pd, Pt). Chem. Commun., 1873-1874; (b) Lewis, A.L., Orpen, A.G., Rotter, S., Starbuck, J., Wang, X.M., Rodriguez-Martin, Y., and Ruiz-Perez, C. (2000) Organic-inorganic hybrid solids: control of perhalometallate solid state structures. J. Chem. Soc., Dalton Trans., 3897-3905; (c) Dolling, B., Gillon, A.L., Orpen, A.G., Starbuck, J., and Wang, X.M. (2001) Homologous families of chloride-rich 4,4-bipyridinium salt structures. Chem. Commun., 567-568; (d) Angeloni, A., Crawford, P.C., Orpen, 
A.G., Podesta, T.J., and Shore, B.J. (2004)

Does hydrogen bonding matter in crystal engineering? Crystal structures of salts of isomeric ions. Chem. Eur. J., 10, 3783-3791.

27 (a) Podesta, T.J. and Orpen, A.G. (2005) Tris(pyridinium)triazine in crystal synthesis of 3-fold symmetric structures. Cryst. Growth Des., 5, 681-693; (b) Adams, C.J., Crawford, P.C., Orpen, A.G., Podesta, T.J., and Salt, B. (2005) Thermal solid state synthesis of coordination complexes from hydrogen bonded precursors. Chem. Commun., 2457-2458; (c) Adams, C.J., Angeloni, A., Orpen, A.G., Podesta, T.J., and Shore, B. (2006) Crystal synthesis of organic-inorganic hybrid salts based on tetrachloroplatinate and -palladate salts of organic cations: formation of linear, two-, and three-dimensional $\mathrm{NH} \cdots \mathrm{Cl}$ hydrogen bond networks. Cryst. Growth Des., 6, 411-422; (d) Adams, C.J., Crawford, P.C., Orpen, A.G., and Podesta, T.J. (2006) Cation and anion diversity in $\left.[\mathrm{M} \text { (dithiooxalate })_{2}\right]^{2-}$ salts: structure robustness in crystal synthesis. Dalton Trans., 4078-4092.

28 (a) Rivas, J.C.M. and Brammer, L. (1998) Self-assembly of 1-D chains of different topologies using the hydrogen-bonded inorganic supramolecular synthons $\mathrm{N}-\mathrm{H} \cdots \mathrm{Cl}_{2} \mathrm{M}$ or $\mathrm{N}-\mathrm{H} \cdots \mathrm{Cl}_{3} \mathrm{M}$. Inorg. Chem., 37, 4756-4757; (b) Zordan, F., Minguez Espallargas, G., and Brammer, L. (2006) Unexpected structural homologies involving hydrogen-bonded and halogenbonded networks in halopyridinium halometallate salts. CrystEngComm, 8, 425-431.

29 (a) Podesta, T.J. and Orpen, A.G. (2002) Use of the Ni(dithiooxalate) ${ }_{2}{ }^{2-}$ unit as a molecular tecton in crystal engineering. CrystEngComm, 4, 336-342; (b) Crowford, P.C., Gillon, A.L., Green, J., Orpen, A.G., Podesta, T.J., and Pritchard, S.V. (2004) Synthetic crystallography. synthon mimicry and tecton elaboration in metallate anion salts. CrystEngComm, 6, 419-428.

30 Imaz, I., Thillet, A., and Sutter, J.-P. (2007) Charge-assisted hydrogen-bonded assemblage of an anionic $\left\{\mathrm{M}\left(\mathrm{C}_{2} \mathrm{O}_{4}\right)_{4}\right\}^{4-}$ building unit and organic cations: a versatile approach to hybrid supramolecular architectures. Cryst. Growth Des., 7, 1753-1761.

31 (a) Wang, X.-Y. and Sevov, S.C. (2007) Hydrogen-bonded host frameworks of cationic metal complexes and anionic disulfonate linkers: effects of the guest molecules and the charge of the metal complex. Chem. Mater., 19, 4906-4912; (b) Wang, X.-Y. and Sevov, S.C. (2008) Synthesis, structures, and magnetic properties of metal-coordination polymers with benzenepentacarboxylate linkers. Inorg. Chem., 47, 1037-1043; (c) Wang, X.-Y. and Sevov, S.C. (2008) A series of guest-defined metal-complex/disulfonate frameworks of hydrogen-bonded [Co $\left.(\mathrm{en})_{2}(\mathrm{ox})\right]^{+}$and 2,6naphtalenedisulfonate. Cryst. Growth Des., 8, 1265-1270; (d) Forbes, T.Z. and Sevov, S.C. (2009) Metal-organic frameworks with direct transition metal-sulfonate interactions and charge-assisted hydrogen bonds. Inorg. Chem., 48, 6873-6878.

32 (a) MacDonald, J.C., Dorrestein, P.C., Pilley, M.M., Foote, M.M., Lundburg, J.L., Henning, R.W., Schutlz, A.J., and Manson, J.L. (2000) Design of layered crystalline materials using coordination chemistry and hydrogen bonds.

J. Am. Chem. Soc., 122, 11692-11702;

(b) Luo, T-J.M., MacDonald, J.C., and Palmore, G.T.R. (2004) Fabrication of complex crystals using kinetic control, chemical additives, and epitaxial growth. Chem. Mater., 16, 4916-4927.

33 Noveron, J.C., Lah, M.S., Del Sesto, R.E., Arif, A.M., Miller, J.S., and Stang, P.J. (2002) Engineering the structure and magnetic properties of crystalline solids via the metal-directed self-assembly of a versatile molecular building unit. J. Am. Chem. Soc., 124, 6613-6625.

34 Dalrymple, S.A. and Shimizu, G.K.H. (2007) Crystal engineering of a permanently porous network sustained exclusively by charge-assisted hydrogen bonds. J. Am. Chem. Soc., 129, 12114-12116.

35 Brand, G., Hosseini, M.W., Ruppert, R., De Cian, A., Fischer, J., and Kyritsakas, N. (1995) A molecular approach to organic solids: molecular recognition of arene 
sulfonate by a bis-cyclic amidinium in the solid state. New J. Chem., 19, 9-13.

36 Félix, O., Hosseini, M.W., De Cian, A., and Fischer, J. (1998) Molecular tectonics VIII: formation of 1D and 3D networks based on the simultaneous use of hydrogen bonding and electrostatic interactions. New J. Chem.,

22, 1389-1393.

37 Hosseini, M.W. (2003) Molecular tectonics: from molecular recognition of anions to molecular networks. Coord. Chem. Rev., 240, 157-166.

38 (a) Hosseini, M.W., Ruppert, R., Schaeffer, P., De Cian, A., Kyritsakas, N., and Fischer, J. (1994) A molecular approach to the solid state synthesis: prediction and synthesis of self-assembled infinite rods. Chem. Commun., 2135-2136; (b) Brand, G., Hosseini, M.W., Ruppert, R., De Cian, A., Fischer, J., and Kyritsakas, N. (1995) A molecular approach to organic solids: molecular recognition of arene sulfonate by a bis-cyclic amidinium in the solid state. New J. Chem., 19, 9-13; (c) Félix, O., Hosseini, M.W., De Cian, A., and Fischer, J. (1997) Molecular tectonics IV: molecular networks based on hydrogen bonding and electrostatic interactions. Tetrahedron Lett., 38, 1755-1758; (d) Félix, O., Hosseini, M.W., De Cian, A., and Fischer, J. (1997) Molecular tectonics V: molecular recognition in the formation of molecular networks based on hydrogen bonding and electrostatic interaction. Tetrahedron Lett., 38, 1933-1936; (e) Félix, O., Hosseini, M.W., De Cian, A., and Fischer, J. (1997) Molecular tectonics III: the simultaneous use of $\mathrm{H}$-bonding and charge-charge interactions for the self-assembly of fumaric acid and cyclic bisamidinium into one- and two-dimensional molecular networks. Angew. Chem., Int. Ed. Engl., 36, 102-104; (f) Félix, O., Hosseini, M.W., De Cian, A., and Fischer, J. (2000) Crystal engineering of 2-D hydrogen bonded molecular networks based on the selfassembly of anionic and cationic modules. Chem. Commun., 281-282; (g) Félix, O., Hosseini, M.W., and De Cian, A. (2001) Design of 2-D hydrogen bonded molecular networks using pyromellitate dianion and cyclic bisamidinium dication as complementary tectons. Solid State Sci., 3, 789-793.

39 (a) Hosseini, M.W., Brand, G., Schaeffer, P., Ruppert, R., De Cian, A., and Fischer, J. (1996) A molecular approach to solid structures II: prediction and synthesis of sheets through assembly of complementary molecular units. Tetrahedron Lett., 37, 1405-1408; (b) Ball, V., Planeix, J.-M., Félix, O., Hemmerle, J. Schaaf, P., Hosseini, M.W., and Voegel, J.-C. (2002) Molecular tectonics: abiotic control of hydroxyapatite crystals morphology. Cryst. Growth Des., 2, 489-492; (c) Planeix, J.-M., Jaunky, W., Duhoo, T., Czernuszka, J., Hosseini, M.W., and Brès, E.F. (2003) A molecular tectonics crystal engineering approach for building organic inorganic composites. Potential application to the growth control of hydroxyapatite crystals. J. Mater. Chem., 13, 2521-2524.

40 Shacklady, D.M., Lee, S.-O., Ferlay, S., Hosseini, M.W., and Ward, M.D. (2005) Translational design and bimodal assembly of hydrogen-bonded networks. Cryst. Growth Des., 5, 995-1003.

41 Félix, O., Hosseini, M.W., De Cian, A., Fischer, J., Catala, L., and Turek, P. (1999) Synthesis, structural and EPR analysis of nitronyl-nitroxide labelled isophthalic acid. Tetrahedron Lett., 41, 2943-2946.

42 Hosseini, M.W., Tsiourvas, D., Planeix, J.-M., Sideratou, Z., Thomas, N., and Paleos, C.M. (2004) Design of liquid crystals based on a combination of hydrogen bonding and ionic interactions. Collec. Czech. Chem. Commun., 69, 1161-1168.

43 Braga, D., Maini, L., Grepioni, F., De Cian, A., Felix, O., Fischer, J., and Hosseini, M.W. (2000) Charge-assisted N-H-O and $\mathrm{O}-\mathrm{H}-\mathrm{O}$ hydrogen bonds control the supramolecular aggregation of ferrocene dicarboxylic acid and bis-amidines. New J. Chem., 24, 547-553.

44 Carpanese, C., Ferlay, S., Kyritsakas, N., Henry, M., and Hosseini, M.W. (2009) Molecular tectonics: design of 2-D networks by simultaneous use of charge-assisted hydrogen and coordination bonds. Chem. Commun., 2514-2516. 
45 Paraschiv, C., Ferlay, S., Hosseini, M.W., Kyritsakas, N., Planeix, J.-M., and Andruh, M. (2007) Hybrid organic/inorganic Hbonded supramolecular networks including $\left[\mathrm{Cr}(\mathrm{ox})_{2} \mathrm{~L}\right]^{-}(\mathrm{L}=1,10$ phenanthroline and 2,2 $2^{-}$-bipyridine) tectons. Rev. Roum. Chim., 52, 101-104.

46 Félix, O., Hosseini, M.W., De Cian, A., and Fischer, J. (1997) A molecular approach to organic solids: synthesis of phenyl di- and tri-carbo xamidines. New J. Chem., 21, 285-288.

47 Marinescu, G., Ferlay, S., Kyritsakas, N., and Hosseini, M.W. (2008) Molecular tectonics: design and generation of charge assisted $\mathrm{H}$ bonded hybrid molecular networks based on amidinium cations and thio- or isothio-cyanatometallates. Dalton Trans., 615-619.

48 (a) Decurtins, S., Schmalle, H.W., Oswald, H.R., Linden, A., Enseling, J., and Gütlich, P. (1994) A polymeric two-dimensional mixed-metal network. Crystal structure and magnetic properties of $\left\{\left[\mathrm{P}(\mathrm{Ph})_{4}\right]\right.$ $\left.\left[\mathrm{MnCr}(\mathrm{ox})_{3}\right]\right\}$. Inorg. Chim. Acta, 216, 65-73; (b) Decurtins, S., Schmalle, H.W., and Pellaux, R. (1998) Polymeric two- and three-dimensional transition-metal complexes comprising supramolecular host-guest systems. New J. Chem., 117-121.

49 (a) Ferlay, S., Félix, O., Hosseini, M.W., Planeix, J.-M., and Kyritsakas, N. (2002) Second sphere supramolecular chirality: racemic hybrid H-bonded 2-D molecular networks. Chem. Commun., 702-703; (b) Dechambenoit, P., Ferlay, S., Hosseini, M.W., and Kyritsakas, N. (2008) Molecular tectonics: control of reversible water release in porous charge-assisted $\mathrm{H}$ bonded networks. J. Am. Chem. Soc., 130, 17106-17113.

50 Dechambenoit, P., Ferlay, S., Hosseini, M.W., Planeix, J.-M., and Kyritsakas, N. (2006) Molecular tectonics: control of packing of hybrid 1-D and 2-D H-bonded molecular networks formed between bisamidinium dication and cyanometallate anions. New J. Chem., 30, 1403-1410.

51 Ferlay, S., Bulach, V., Félix, O., Hosseini, M.W., Planeix, J.-M., and Kyritsakas, N. (2002) Molecular tectonics and supramolecular chirality: rational design of hybrid 1-D and 2-D H-bonded molecular networks based on bisamidinium dication and metal cyanide anions. CrystEngComm, 447-453.

52 Dechambenoit, P., Ferlay, S., Hosseini, M.W., and Kyritsakas, N. (2010) Molecular tectonics: crystal engineering of mixed valence $\mathrm{Fe}(\mathrm{II}) / \mathrm{Fe}(\mathrm{III})$ solid solutions. Chem. Commun., 46 (6), 868-870.

53 Ferlay, S., Holakovsky, R., Hosseini, M.W., Planeix, J.-M., and Kyritsakas, N. (2003) Charge assisted chiral hybrid $\mathrm{H}$-bonded molecular networks. Chem. Commun., 1224-1225.

54 Dechambenoit, P., Ferlay, S., Hosseini, M.W., and Kyritsakas, N. (2007) Molecular tectonics: polymorphism and enhancement of networks dimensionality by combination of primary and secondary H-bond sites. Chem. Commun., 4626-4627.

55 Paraschiv, C., Ferlay, S., Hosseini, M.W., Bulach, V., and Planeix, J.-M. (2004)

Molecular tectonics: design of luminescent H-bonded molecular networks. Chem. Commun., 2270-2271.

56 (a) Braga, D., Grepioni, F., and Orpen, A.G. (eds) (1999) NATO ASI Series, vol. 538, Kluwer, Dordrecht, The Netherlands; (b) Seddon, R.K. and Zaworotko, M. (1999) in NATO ASI Series C, vol. 539 (eds D. Braga, F. Grepioni, and G. Orpen), Kluwer, Dordrecht, The Netherlands.

57 (a) Nagasundaram, N., Roper, G., Biscoe, J., Chai, J.W., Patterson, H.H., Blomg, N., and Ludi, A. (1986) Single-crystal luminescence study of the layered compound potassium dicyanoaurate. Inorg. Chem., 25, 2947-2951; (b) Rawashdeh-Omary, M.A., Omary, M.A., and Patterson, H.H. (2000) Oligomerization of $\mathrm{Au}(\mathrm{CN})_{2}{ }^{-}$and $\mathrm{Ag}$ $(\mathrm{CN})_{2}{ }^{-}$ions in solution via ground-state aurophilic and argentophilic bonding. J. Am. Chem. Soc., 122, 10371-10380; (c) Stender, M., Olmstead, M.M., Balch, A.L., Riosb, D., and Attar, S. (2003) Cation and hydrogen bonding effects on the self-association and luminescence of the dicyanoaurate ion, $\left[\mathrm{Ag}(\mathrm{CN})_{2}\right]^{-}$ Dalton Trans., 4282-4287. 
58 (a) Guo, J., Wong, W.-K., and Wong, W.-Y. (2005) Synthesis and structural characterization of some arylamidinium diphenylphosphinates: formation of one-, two-, and three-dimensional networks by charge-assisted hydrogen bonds. Polyhedron, 24, 927-939; (b) Yoshida, Y., Fujii, J., and Saito, G. (2006)

Dicyanoaurate(I) salts with 1-alkyl-3methylimidazolium: luminescent properties and room-temperature liquid forming. J. Mater. Chem., 16, 724-727.

59 (a) Yaghi, O.M., Li, H., and Groy, T.L. (1996) Construction of porous solids from hydrogen-bonded metal complexes of 1,3,5-benzenetricarboxylic acid. J. Am. Chem. Soc., 118, 9096-9101; (b) Aakeröy, C.B., Beatty, A.M., and Leinen, D.S. (1999) A versatile route to porous solids: organic-inorganic hybrid materials assembled through hydrogen bonds. Angew. Chem., Int. Ed., 38, 1815-1819; (c) Maspoch, D., Domingo, N., Ruiz-Molina, D., Wurst, K., Tejada, J., Rovira, C., and Veciana, J. (2004) A robust nanocontainer based on a pure organic free radical. J. Am. Chem. Soc., 126, 730-731; (d) Uemura, K., Kitagawa, S., Fukui, K., and Saito, K. (2004) A contrivance for a dynamic porous framework: cooperative guest adsorption based on square grids connected by amide-amide hydrogen bonds. J. Am. Chem. Soc., 126, 3817-3828; (e) Demers, E., Maris, T., and Wuest, J.D. (2005). Molecular tectonics. Porous hydrogenbonded networks built from derivatives of 2,2',7,7'-tetraphenyl-9,9' -spirobi[ $9 H$ fluorene]. Cryst. Growth Des., 5, 1227-1235; (f) Trolliet, C., Poulet, G., Tuel, A., Wuest, J.D., and Sautet, P. (2007) A theoretical study of cohesion, structural deformation, inclusion, and dynamics in porous hydrogen-bonded molecular networks. J. Am. Chem. Soc., 129, 3621-3626; (g) Stephenson, M.D. and Hardie, M.G. (2007) Network structures with 2,2'-bipyridine-3,3' -diol: a discrete Co (III) complex that forms a porous 3-D hydrogen bonded network, and $\mathrm{Cu}(\mathrm{II})$ coordination chains. CrystEngComm, 9, 496-502.

60 Dechambenoit, P., Ferlay, S., Hosseini, M.W., and Kyritsakas, N. (2009) Playing with isostructurality: from tectons to molecular alloys and composite crystals. Chem. Commun., 1559-1561.

61 (a) Choi, H.J. and Suh, M.P. (2004) Dynamic and redox active pillared bilayer open framework: single-crystal-to-singlecrystal transformations upon guest removal, guest exchange, and framework oxidation. J. Am. Chem. Soc., 126, 15844-15851; (b) Ritchie, C., Streb, C., Thiel, J., Mitchell, S.G., Miras, H.N., Long, D.-L., Boyd, T., Peacock, R.D., McGlone, T., and Cronin, L. (2008) Reversible redox reactions in an extended polyoxometalate framework solid. Angew. Chem., Int. Ed., 47, 6881-6884.

62 Dechambenoit, P., Ferlay, S., Hosseini, M.W., and Kyritsakas, N. (2009) In situ reduction of $\mathrm{Fe}(\mathrm{III})$ into $\mathrm{Fe}(\mathrm{II})$ : an example of post-crystallisation transformation. Chem. Commun., 6798-6800.

63 (a) Braga, D., Cojazzi, G., Paolucci, D., and Grepioni, F. (2001) A remarkable watersoluble (molecular) alloy with two tunable solid-to-solid phase transitions. Chem. Commun., 803-804; (b) Ferlay, S. and Hosseini, M.W. (2004) Crystalline molecular alloys. Chem. Commun. 787-786; (c) Sada, K., Inoue, K., Tanaka, T., Epergyes, A., Tanaka, A., Tohnai, N., Matsumoto, A., and Miyata, M. (2005) Multicomponent organic alloys based on organic layered crystals. Angew. Chem., Int. Ed.,

44, 7059-7052.

64 (a) Maroncelli, M., Strauss, H.L., and Snyder, R.G. (1985) Structure of the $n$ alkane binary solid $n-\mathrm{C}_{19} \mathrm{H}_{40} / n-\mathrm{C}_{21} \mathrm{H}_{44}$ by infrared spectroscopy and calorimetry. J. Phys. Chem., 89, 5260-5267; (b) Dorset, D.L. (1990) Direct structure analysis of a paraffin solid solution. Proc. Natl. Acad. Sci. USA, 87, 8541-8544; (c) Sirota, E.B., King, H.E., Jr., Shao, H.H., and Singer, D.M. (1995) Rotator phases in mixtures of n-alkanes. J. Phys. Chem., 99, 798-808; (d) Mondieig, D., Espeau, P., Robles, L., Haget, Y., Oonk, H.A.J., and CuevasDiarte, M.A. (1997) Mixed crystals of $n$-alkane pairs. A global view of the thermodynamic melting properties. J. Chem. Soc., Faraday Trans., 93, 3343-3346. 
232 7 Molecular Tectonics: Design of Hybrid Networks

65 Dechambenoit, P., Ferlay, S., and Hosseini, M.W. (2005) From tectons to composite crystals. Cryst. Growth Des., 5, 2310-2312.

66 Vegard, L. (1921) Gitterkonstanten von mischkristallen. Z. Phys., 5, 17-26.

67 (a) Bonafe, S.J. and Ward, M.D. (1995) Selective nucleation and growth of an organic polymorph by ledge-directed epitaxy on a molecular crystal substrate. J. Am. Chem. Soc., 117, 7853-7861; (b) Mitchell, C.A., Yu, L., and Ward, M.D. (2001) Selective nucleation and discovery of organic polymorphs through epitaxy with single crystal substrates. J. Am. Chem. Soc., 123, 10830-10839.

68 (a) Swalen, J.D. (1991). Materials assembly and formation using engineered polypeptides. Annu. Rev. Mater. Res., 34, 373-408; (b) Forrest, S.R. (1997) Ultrathin organic films grown by organic molecular beam deposition and related techniques. Chem. Rev., 97, 1793-1896; (c) Hooks, D., Fritz, T., and Ward, M.D. (2001) Epitaxy and molecular organization on solid substrates. Adv. Mater., 13, 227-241.

69 (a) Furukawa, S., Hirai, K., Nakagawa, K., Takashima, Y., Matsuda, R., Tsuruoka, T., Kondo, M., Haruki, R., Tanaka, D., Sakamoto, H., Shimomura, S., Sakata, O., and Kitagawa, S. (2008) Heterogeneously hybridized porous coordination polymer crystals: fabrication of heterometallic core-shell single crystals with an in-plane rotational epitaxial relationship. Angew. Chem., Int. Ed., 47, 1766-1770;

(b) Catala, L., Brinzei, D., Prado, Y., Gloter, A., Stéphan, O., Rogez, G., and Mallah, T. (2009) Core-multishell magnetic coordination nanoparticles: toward multifunctionality on the nanoscale. Angew. Chem., Int. Ed., 48, 183-187;

(c) Furukawa, S., Hirai, K., Takashima, Y., Nakagawa, K., Kondo, M., Tsuruoka, T., Sakata, O., and Kitagawa, S. (2009) A block PCP crystal: anisotropic hybridization of porous coordination polymers by face-selective epitaxial growth. Chem. Commun., 5097-5099; (d) Koh, K., Wong-Foy, A.G., and Matzger, A.J. (2009) MOF@MOF: microporous core-shell architectures. Chem. Commun., 6162-6164.

70 Brès, E.F., Ferlay, S., Dechambenoit, P., Leroux, H., Hosseini, M.W., and Reyntjens, S. (2007) Playing with isostructurality: from tectons to molecular alloys and composite crystals. J. Mater. Chem., 17, 1559-1561.

71 Olmsted, B.K., Ferlay, S., Dechambenoit, P., Hosseini, M.W., and Ward, M.D. (2009) Microscopic topography of heterocrystal interfaces. Cryst. Growth Des., 6, 2841-2847. 